UC3M Working papers

Economic

$13-16$

July, 2013
Departamento de Economía

Universidad Carlos III de Madrid

Calle Madrid, 126

28903 Getafe (Spain)

Fax (34) 916249875

\title{
Altitude as handicap in rank-order football tournaments.
}

\author{
Agustin Casas* \\ Yarine Fawaz $^{\dagger}$
}

July 29, 2013

\section{Abstract}

In 2007, based on medical reports, FIFA ruled that no international football competition could be played in stadiums with an altitude higher than 2500 meters. We provide stark evidence which supports the claim that playing in high altitude benefits the home team through two channels. First, in these scenarios, high altitude teams (HAT) do better against low altitude teams than against other high altitude teams. Second, every time that low altitude teams visit other high altitude teams they get fewer points than if they had played in a low altitude stadium. Therefore, the HAT go up in the ranking of the southamerican qualifiers for world cups, not only because of their own extra-advantage of playing in high altitudes, but also because the LAT do worse in all high altitude stadiums. According to our work, have this ruling taken effect, Ecuador would not have gone to the 2006 world cup, and therefore Ecuador's Football Federation would have lost at least 40 million dollars given out by FIFA to all teams going to the world cup.

\footnotetext{
* Universidad Carlos III de Madrid, mailto: acasas@eco.uc3m.es

+ Universitat Autonoma de Barcelona, mailto: yarine.fawaz@uab.cat
} 


\section{Introduction}

Since Lazear and Rosen (1981), the theory on rank-order tournaments poses that, under the presence of heterogeneous players, handicapping the highest quality players is a welfare enhancing reform. Along these lines, Che and Gale (2003) proves that handicapping the most efficient supplier might be optimal in procurement auctions, while Knoeber and Thurman (1994) show that tournament organizers intend to handicap the most productive players in order to increase broiler production. The reasoning behind these results is that handicapping the best players makes tournaments more "competitive" and, therefore, it induces higher effort from low and high quality players. As it is often the case, a natural ground to test predictions from contest theory is that of sports: we look at the South American football tournaments that determine the participants in the FIFA World Cups. In particular, we study whether playing in high altitude cities (such as Bogota, Quito and La Paz) constitutes a handicap to the national football teams that do not play often in these cities, and whether it renders these tournaments more competitive. $^{1}$

Furthermore, we explore a change in the tournament structure that, we argue, has improved the efficiency of these tournaments: from a seeded contest in which teams were split in 2 groups, to a double round-robin system, where all teams play against each other. We show that, in line with the predictions of contest theory and empirical applications (Levy and Vukina (2004)), this change has mitigated the group composition effects while intensifying the altitude advantage. That is, we provide evidence that the recent changes in the South American qualifiers has only strengthened the handicap despite FIFA's efforts to prohibit playing in high altitude cities.

International South American football (or soccer) competitions are unique in the sense that some teams have their home stadiums in the ladders of the Andes Mountains, and therefore play most of their home matches in high altitude scenarios. Bolivia's national football teams has always played their home games in La Paz (3,600 meters), while Colombia's and Ecuador's have one of their home stadiums just above 2,500 meters (2,600 mts Bogota and 2,800 mts Quito, respectively). Although the medical community and the "sea-level" athletes have pointed out that this may not only constitute an artificial advantage but also a health risk, the International Football Federation (FIFA) has failed in its attempts to ban those scenarios. The main argument for continuing to use these high altitude stadiums is that, if any, those disadvantages could be understood as part of the widely documented home advantage that all teams enjoy, popularly known as the home bias.

In this paper, we make a novel use of publicly available data for the South American qualifiers to the FIFA World Cups from 1954 to 2010 to show that it is possible to disentangle the home bias advantage from the altitude advantage. While the home bias constitutes an extra advantage for all teams when they play in their home stadium, we show that the altitude advantage is only enjoyed by Ecuador and Bolivia when they play against the other teams in a high altitude

\footnotetext{
${ }^{1}$ For more applications of optimal contest design to sports tournaments see Szymanski (2003), which points out that handicapping the best teams increases the competitive balance of the tournament, it does not need to be positively related to profits.
} 
city. Therefore, we show that altitude is a handicap for all teams other than Ecuador and Bolivia.

However, previous studies in economics has failed in providing a sound measure of this handicap. Specifically, the existing literature has not succeeded in identifying simultaneously, but separately, the home bias and the altitude advantage. Our contribution stems not only from showing that altitude does constitute a handicap but also from identifying the effect of altitude on teams' performance by exploiting some features of the data that have not been used before. In particular we explore three identification avenues: 1) the changes of host cities (and so of their altitudes) within a country, 2) the variation across teams in adaptation to altitude, and 3) the tournament structure, which makes each couple of teams face each other once home and once away. In the extensions we also exploit the panel structure of the data, and investigate the effects of incorporating tournaments with a different structure (from 1954 to 1994). Despite these innovations, consistently with previous research, teams' quality and the home bias have the strongest explanatory power in our regressions.

A novelty of our approach is to treat each game as two different but correlated observations, in a similar way as Pettersson-Lidbom and Priks (2010) do implicitly. One game between team $\mathrm{A}$ and team $\mathrm{B}$ played in city $\mathrm{C}$ will be considered twice, once as "Team A versus Team B in city C", then as "Team B versus Team A in city C". One consequence of such an organization is that while the home variable will vary between these two observations of one game (home being a dummy coded 1 when team A plays home), altitude will not, since it is related to the city where the game is played. This strategy allows us to identify the home bias and the altitude advantage, while allowing to split the altitude advantage in two effects. The individual payoff in rank-order tournaments depends not only on the own performance against the other players (the direct effect), but also on the other players' performance against the remaining players (the indirect effect). In our case, the direct advantage takes place when a "high altitude team" makes more points when it plays at home in a "high altitude city", than if it had played in a "low altitude city". The indirect advantage occurs when the ranking of these high altitude teams ( $H A T$ for easy of use) goes up due to the points lost by the low altitude teams $(L A T)$ when they play away games against other HATs in high altitude cities. Thus, since what matters in the tournaments is the relative ranking at the end of the competition, the individual advantage of a $H A T$ is the sum of the increased points it gets from playing in altitude against LATs, plus the reduction of the points experienced by the $L A T \mathrm{~s}$ for playing in altitude against other HATs.

In more general terms, the introduction of three high altitude cities (as it is the case in the South American qualifiers) may benefit all high altitude teams greatly by increasing their relative ranking. However, if more teams with an altitude advantage were introduced, the incumbent HATs may be hurt, suggesting that there is an optimal number of asymmetries for the benefited teams, as suggested in McLaughlin (1988).

Our results indicate that the handicap on individual physical performance due to mountain sickness (as shown in medical journals) has a large effect on team performance. For all the 
specifications we have estimated, teams that are not used to play in high altitudes are less likely to win in high altitude stadiums, even controlling for the home bias. Moreover, the predictions from our main regression indicates that Bolivia and Ecuador would not have obtained a significant amount of points if they had always played their home games at sea level. For instance, 4 out of 8 home victories in Ecuador could be attributed to Quito's altitude, while 5 out of 6 home victories in Bolivia could be attributed to La Paz's altitude. Besides, according to our estimates, Ecuador would not have qualified to the 2002 and 2006 FIFA world cups. Nevertheless, we pose that the existence of a strong altitude advantage constitutes the best argument for not banning high altitude stadiums from international competitions as they may induce higher effort, a more even competition and, as a result, they may draw larger audiences to this tournament ${ }^{2}$.

The remainder of the paper is structured as follows. In the next section we provide a brief overview of the existing literature on the effects of altitude and home bias on sports outcomes, and detail the institutional background of the qualifiers set-up we use in this paper. Section 3 describes the data, discusses the identification strategy, and highlights the main results. Finally, section 4 contains a number of interesting extensions to our central econometric strategy, amongst which an ordered probit estimation and some other robustness checks.

\section{Literature review and institutional background}

\subsection{Related literature}

As pointed above, the medical literature in the topic is clear regarding the effect of altitude on physical performances without previous acclimatization: aerobic capacity is substantially reduced (Brutsaert et al. (2008)), and in particular time for recovery is longer (Levine et al. (2008)). These effects can be avoided with an acclimatization period of one or two weeks, depending on the altitude. Despite the availability of the data, the sports literature on the topic is scarce and inconclusive, specially for not have taken advantage of the structure of the data properly. For instance, McSharry (2007) find a negative and continuous effect of altitude on performance, without controlling for the teams' quality or acknowledging neither that Colombia and Ecuador change their home stadium between low and high altitude locations nor that the altitude and the home bias coefficients might be confused. On the other hand, Chumacero (2009) finds no effect of altitude.

More generally, regarding the study of sports economics, two main approaches have been taken in the literature. Both of them deal with each game as being one observation, while generally the two teams obtain different results, and score a different number of goals. One approach intends to explain the exact score of the game (that is, they are interested in the final score 4-1 rather than "home win"). In those cases, the explained variable is modelled as a bivariate Poisson (or Binomial) where the goals suffered and scored by a team in a given game

\footnotetext{
${ }^{2}$ For a counter-argument see Szymanski (2003), who claims that competitive balance does not necessarily draw larger audiences and/or profits.
} 
are treated as independent events (Chumacero (2009)). Such assumption -that the number of goals scored by the two teams are independent of each other- is a strong one, as shown in Karlis and Ntzoufras (2003), since the probability of a team scoring is higher after suffering a goal than before. Furthermore, rather than explaining the final score, our main interest is in explaining the effect of altitude on the relative ranking in tournaments through the match outcome (measured as lose/tie/win).

The other approach that treats each game as one observation fixes the home team result (lose/tie/win) as the outcome of interest. In this literature the home bias might be confounded either with altitude (Chumacero (2009)), team characteristics (Williams (2011)), or the constant term, among other things. A related problem is that this approach fails to study the performance of away teams, which in our case would be a problem as we need to compare the performance of team A with rival B playing at high altitude with the same team A playing at low altitude against the same team $B$. If we do not observe the away behavior of teams we miss half the information, and we would not be able to correctly identify the variables of interest. Our treatment of the data will allow us to identify not only the increased performance of the high altitude teams playing at home, but also by how much the away teams are hurt, when they are low altitude teams. ${ }^{3}$

To our knowledge the only paper that has profited from using the football in a fashion similar to ours is Pettersson-Lidbom and Priks (2010). They exploit an exogenous variation in the attendees to some games in the Italian league to identify the cause of the home bias. This paper, as well as Garicano et al. (2005), shows that referees are influenced (i.e. pressured) by the home fans to favour the local team in their calls, an explanation first studied in Pollard (1986).

\subsection{Institutional background}

FIFA's revenues during the last World Cup were comparable to a small country's GDP, and larger than that of many countries affiliated to FIFA. For any national football federation, making it to the world cup is not only a source of pride and sports chauvinism, but also a source of large revenues in terms of FIFA prizes, advertising contracts, etc. ${ }^{4}$ Taking into consideration this dimension of football, banning the high altitude stadiums has become a complicated matter for FIFA officials. In 2007, based on medical reports, FIFA ruled that no international football competition could be played in stadiums with an altitude higher than 2500 meters. By the time FIFA tried to impose such ban, Bolivia's national football teams had always played their home games in La Paz (3600 meters), while Colombia's and Ecuador's had one of their home

\footnotetext{
${ }^{3} \mathrm{~A}$ third approach is to constrain the team coefficients (time-varying quality or team-specific fixed effects) to be the same at home and away. This assumption is plausible, but it does not take into account "game depending incentives (for instance, Eugster et al. (2011) disregards the effect of incentives in the second leg of a playoff stage at the UEFA cup).

${ }^{4}$ Only for qualifying to the 2010 World Cup, FIFA paid around 40 million dollars to each national federation as prizes. Then, these federations also make money out of advertising revenues. Moreover, the benefits are both institutional and individual: if they do well in the world cup, players and coaches can be transferred to better club teams, their wages can go up, etc. To sum up, going to the world cups represents a large business for all the involved parts.
} 
stadiums just above 2500 meters (2600 mts Bogota and 2800 mts Quito, respectively).

There are 208 football federations associated to FIFA. The estimated 2010 FIFA's revenues were 4,100 million dollars, out of which roughly the half was made during the world cup in South Africa. Out of the 208 affiliated countries, as of today, only 32 teams participate in the FIFA World Cup that takes place every four years. Broadly, each continent has a supranational organization that organizes a tournament to decide which teams would make it to the following World Cup. There is a total of 6 continental federations affiliated to FIFA (CAF for Africa, CONCACAF for North America, Central America and the Caribbean, CONMEBOL for South America, OFC for Oceania, AFC for Asia and UEFA for Europe). Since 1995, the South American qualifier organized by CONMEBOL is a double round robin system (a standard home and away league tournament) where the first four spots give a direct qualification to the World Cup, and the fifth team qualifies if it wins a match-up against a team from another continental federation (in general from OFC).

The qualifiers for the 1998, 2002, 2006, and 2010 World Cups. These 4 qualifiers are the only ones that kept the structure of tournament relatively constant. All teams (9 teams for the 1998 qualifiers, since Brazil was already classified for being the defending world champion, and 10 for the remaining ones) play against each other, one game at a "home" stadium (that is in their own country) and one "away" (i.e. abroad). According to FIFA rules, during these tournaments, teams get 3 points for winning an official game, 1 for tying, and 0 for losing. Furthermore, the qualifiers are played during the four calendar years between World Cups.

The qualifiers before the $\mathbf{1 9 9 4}$ World Cup. Every four years, since the 1954 World Cup until the 1994 World Cup, 10 qualifiers tournaments have been played in South America. Each tournament was different to the other one, either in structure or the games played (number of games and/or matches). Teams were usually seeded in different groups (from 2 to 5 teams, depending on the tournament) to compete against each other. For most cases, the best teams from each group would qualify directly to the World Cup. With respect to the newer tournaments, during these competitions teams would only get 2 points for a win instead of 3 . Furthermore, for the CONMEBOL qualifiers, the South American teams used to play all their qualifying games in one or two months.

\section{Econometric strategy and results}

In this section we introduce our main linear model, where we treat the data as a pooled cross section and we obtain a diff-in-diff estimation of the altitude advantage, by country. Using these intermediate results, we split the sample between low altitude teams (LATs) and high altitude teams (HATs), and we run similar regressions taking into account this ex-post grouping. Following this strategy allows us to increase the sample size of the treatment and control groups, and therefore to get more precise estimates by reducing their standard errors. By estimating 
a fewer number of coefficients and increasing their significancy, we aim at rendering our model clearer, and the interpretation more intuitive.

\subsection{Data}

In this section we use public data from the last 4 South American qualifiers to the FIFA world cups. Each tournament had 16 or 18 games played by each team, in a league format (one home and one away game against each rival national federation). We first use only these data as in these 4 cases the tournament structure was constant and the games are comparable across tournaments. In a latter section, we also incorporate games from all other qualifier tournaments ever played in South America (since 1954), where the structure of the tournaments has changed for almost every qualifier tournament. ${ }^{5}$ For each game, we also have information of the city where it was played, which allows us to control for altitude. Last, we use the FIFA World rankings to control for time-varying aspects of teams' quality.

At this point, a few precisions could be made as to our handling of the data. The data has been duplicated so that one game corresponds to two observations. Why we chose to do so, and how it makes our identification strategy possible, should be fully explained. Without duplicating the data, we cannot introduce a Home dummy indicating whether the team whose points we are investigating is playing at home or away. This team would always be either the home team, or the away team. Say we look at how many points the home team scores. If we control for team fixed effects as we do in our model, we then get for each team a coefficient that is a mix of team quality, and home bias, without being able to disentangle one from the other. Moreover, even if we were not interested in identifying the home bias, the altitude advantage could not be identified without duplicating the data. Introducing an Altitude dummy as well as interactions between home and away teams and Altitude would be possible, but there would be no way of identifying which part of the positive (resp. negative) effect of altitude is due to playing in altitude and which part comes from playing home (resp. away). As a consequence, one game between Argentina and Brasil played in Rio de Janeiro (Brasil) will be two observations, one where the incumbent team -i.e the team whose points we study- is Argentina and the rival is Brasil, the other where the incumbent is Brasil and the rival is Argentina. Both observations correspond to one game played in Rio de Janerio ${ }^{6}$. This data structure will allow us to investigate the impact of altitude on one team's outcome, while not constraining that team to always be the home team (or the away team), hence allowing us to disentangle the altitude bias, if any, from the home bias. Still, each game will be given an identifier number, and two observations corresponding to one game will of course be considered as correlated. One consequence of such an organization is that while the home variable will vary "within-identifier", altitude will not. Therefore, the home bias will be identified from within and between variation while the altitude bias will be identified using between-variations only.

\footnotetext{
${ }^{5}$ That constitutes a problem since we have fewer observations and we cannot control so easily for team's quality as not all the national federations faced each other.

${ }^{6}$ This should not to be confused with the fact that one game between Brasil and Argentina will be played first in Brasil and then in Argentina, or the other way around.
} 
In all of the following analyses, the dependent variable will be the outcome of a game. In the linear regressions, we define the outcome of a game as the number of points obtained by the incumbent team. ${ }^{7}$ All the information used in the paper is publicly available at FIFA.com.

Figure (1) gives preliminary evidence that the teams that we classify ex-ante as high altitude teams (Bolivia, Colombia and Ecuador) do much better when they play in high altitude stadiums than when they play at sea level (low altitude stadiums). On the other hand, it is also the case that Bolivia played all the home games in high altitude in La Paz, so that their better performance in high altitude may be explained either by their adaptation to altitude or by the so-called home advantage.

Figure 1: Outcomes for HAT vs LAT, by altitude level

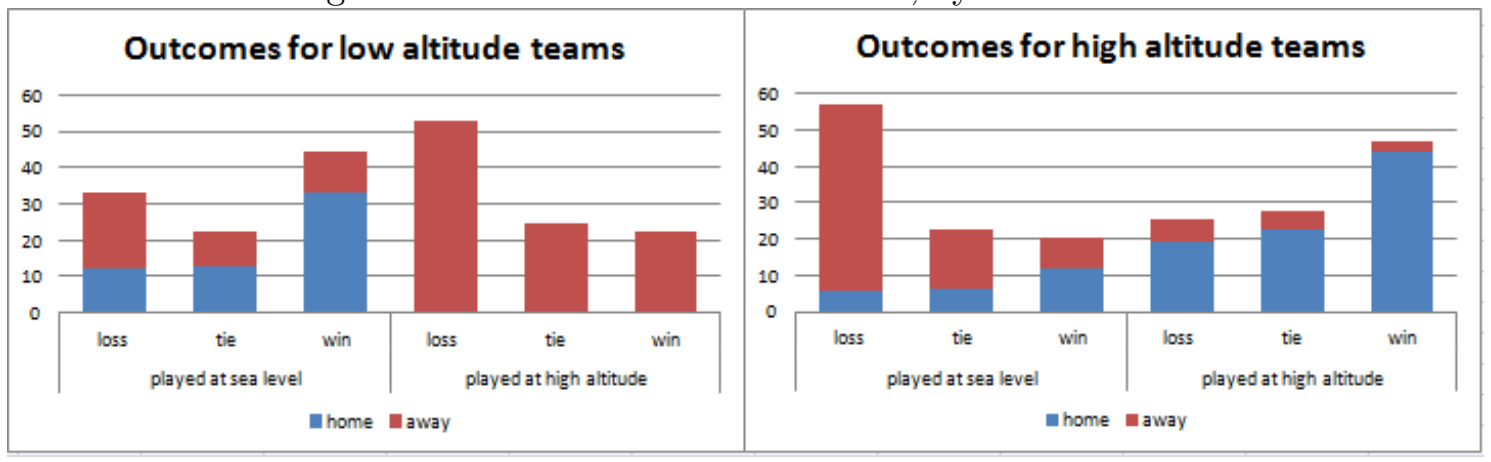

In other words, as the raw data shows, home teams win more often, but high altitude teams win even more often in high altitude stadiums (see table 7 in the appendix). Naturally, there are confounded effects like team quality, home bias, and possibly altitude advantage. Hence the need to resort to the following multivariate analysis in order to be able to disentangle these two effects.

\subsection{Econometric strategy and identification}

In this section the dependent variable, Points $s_{i n c, g}$, is the number of points the incumbent team gets from playing in game $g$, defined as a game played between that team and one rival team in a city $c$. It is coded 0 for losing, 1 for a tie, 3 for a win. So, more precisely, the team whose points are investigated, and the rival team are one of the following set:

Teams $=\{$ Argentina, Bolivia, Brasil, Chile, Colombia, Ecuador, Paraguay, Peru, Uruguay, Venezuela $\}$.

Our key explanatory variables are a dummy for altitude, $H A C$, coded 1 if city $c$ is a high altitude city, i.e. Bogota, Quito, o La $\mathrm{Paz}^{8}$; and the interactions between the altitude variable

\footnotetext{
${ }^{7}$ Later on, in the ordered probit specifications, the outcome of a game will be coded qualitatively: the incumbent either loses, ties, or wins. At last, we also test whether altitude has an effect on the goal difference, and we show that the results do not change significantly when we exploit the panel structure of the data, nor when we add the games from before 1994 .

${ }^{8}$ Alternatively, we test another specification of the altitude variable, coded 0 when the game is played at sea-level, 1 when played in Quito or Bogota, and 2 in La Paz
} 
and team dummies $I n c_{i}$, coded 1 when the incumbent team is $i, i \in$ Teams. The latter interactions allow the impact of altitude on one team's performance to differ between teams.

On top of these variables, we add a set of control variables $X_{g}$, such as team dummies for the rival team, an indicator for the incumbent team playing home, and the rank of each team in the previous year FIFA classification, in order to control for the time-varying component of teams' quality. ${ }^{9}$ Each team is ranked from 1 to 127 , where 1 is the best team.

Our working model for the main linear estimation, where we allow the impact of altitude to be team-specific, is the following:

$$
\begin{array}{r}
\text { Points }_{\text {inc }, g}=\alpha+\sum_{i \in \text { Teams }} \beta_{i} \text { Inc }_{i}+\gamma H A C_{g}+\sum_{i \in \text { Teams }} \beta_{i}^{\text {alt }} \text { Inc }_{i} * H A C_{g} \\
+\delta X_{g}+u_{i n c, g}
\end{array}
$$

Thus, the $\beta_{i}$ capture the fixed component of team quality over time: the better the incumbent team $i$ performs in general (i.e. time-invariantly), the higher $\beta_{i}$ and the higher Points inc, when the incumbent team is $i$. Including dummies for the rival -ie. the team the incumbent team plays against- is not necessary because as mentioned before every team is considered in both incumbent and rival positions, but we still include it in $X_{g}$ for clarity and completeness. ${ }^{10}$

The impact of playing in high altitude for $i n c_{i}$ can be written as: ${ }^{11}$

$$
\begin{aligned}
\beta_{i}^{a l t} & =\left(E\left[\text { Point }_{i n c, g} \mid X_{g}, H A C_{g}=1, i n c_{i}=1\right]-E\left[\text { Points }_{i n c, g} \mid X_{g}, H A C_{g}=0, \text { inc }_{i}=1\right]\right) \\
& -\left(E\left[\text { Points }_{i n c, g} \mid X_{g}, H A C_{g}=1, \text { inc }_{i}=0\right]-E\left[\text { Points }_{\text {inc }, g} \mid X_{g}, H A C_{g}=0, \text { inc }_{i}=0\right]\right)
\end{aligned}
$$

Here it is important to understand that this coefficient reflects the differential impact of playing in altitude for incumbent i $\left(i n c_{i}\right)$ compared to some omitted team . To avoid perfect collinearity, one of the teams must be dropped from the model, therefore becoming the "omitted" group, which can be chosen for clarity purpose. Once the omitted team is chosen, the differential of the impact of altitude for $i n c_{i}$ compared to $i n c_{j}$ is given by $\beta_{i}^{\text {alt }}-\beta_{j}^{\text {alt }}$. In other words, we use a kind of "diff-in-diff" set-up, where $i n c_{i}$ is the team fixed effect, $H A C_{g}$ the treatment indicator, and the interaction between the two yields coefficient $\beta_{i}^{\text {alt }}$. The identifying assumption for this coefficient to be unbiased is therefore that $E\left[u \mid i n c_{i} * H A C_{g}, X_{g}\right]=0$, meaning that if any unobservable factor affects the outcome, it does so in the same way for the incumbent team in altitude and at sea-level, and in the same way for $i n c_{i}$ and for $i n c_{j}, j \neq i$, once the other variables are controlled for (i.e. Home, Rival, Rank).

\footnotetext{
${ }^{9}$ We do not index the equation by $t$ although we have a panel data structure because we deal with the data as if they were pooled cross-section. Later on, we will provide an explanation why panel methods are not appropriate here. Thus, using the current classification rather than the past one would result in a serious endogeneity bias as the dependent variable participates to the computation of the ranking used as explanatory variable.

${ }^{10}$ Therefore, conversely to the incumbent coefficient, the better the rival is, the harder it will be for the incumbent to get points, and therefore the lower Points $s_{i n c, g}$. We thus expect the coefficients of the incumbent and the rival to have opposite signs.

${ }^{11}$ Here we need to index by $i$ as well as the coefficient is not the same across all teams. $\beta_{i}^{a l t}$ gives the impact of playing in Altitude for $i n c_{i}$.
} 
Potential unobserved factors affecting the outcome of the game could be for example the importance of the game played for the qualifiers (e.g. losing one precise game could eliminate one team while losing at another point of the qualifier would not have any irreversible consequence). Although the latter has no reason to impact differently the outcome for different teams, or at different levels of altitude, we control for "high-stake" games in extensions, and provide evidence that our results are robust. One remaining concern is the quality of the team at the time when the game in played: even controlling for the two teams and where the game is played (city, altitude), some factors make $i n c_{i}$ more likely to win at some period than $i n c_{j}$. To control for this heterogeneity in quality "within-teams", we assign to all teams the number corresponding to their ranking in the FIFA classification from the year prior to the game observed, as a proxy for the time-varying component of team quality. Last, we cluster observations by game, since the errors for one game corresponding to two observations must be correlated.

Although we discuss the main results later, from estimating equation (1) we already know a couple of very interesting things that will remain the same across all specifications: (1) the ex-post ranking of teams, after controlling for home biases and advantages mirrors the FIFA rankings quite accurately (see Table 1 for an overview of the ex-post ranking coming from our estimations). From 1998 to 2010, Brasil, Argentina, and Paraguay were the best teams. The middle quality teams were Colombia, Uruguay and Chile; then Ecuador and Peru, and finally the worst ones were Venezuela and Bolivia. There are a few surprises with respect to the FIFA ranking for the same period: Paraguay ranks better than expected ${ }^{12}$, and Ecuador ranks worse than expected. Ecuador's ranking from the data takes us directly to our second finding: (2) Ecuador and Bolivia come out as high altitude teams, in the sense that these are the two teams that do better than what they would have done, had they played their home games at the sea level. ${ }^{13}$

In the second OLS specification we allow the impact of altitude to differ between highaltitude and low-altitude teams. Teams are sorted into these two groups both on an ex-ante and ex-post basis, i.e. according to their objective altitude level, and then according to the estimates from the first specification. In a nutshell, teams that we classify "ex-ante" as sea-level teams seem to suffer more when playing in altitude than those that we classify as high altitude teams. By ex-ante "sea-level" we mean teams which always play their National Team games at low altitude when playing home (Argentina, Brasil, Chile, Peru, Venezuela, and Uruguay); conversely ex-ante "high-altitude" teams play some games in high altitude scenarios (Colombia and Ecuador) and Bolivia always plays all of their home games for qualifiers in the stadium with the highest altitude in the world. ${ }^{14}$. Therefore, some teams are used to play in high altitude scenarios while some are not. We repeat the exercise taking into account the ex-post grouping (in which Colombia comes out as a LAT, since it does not perform better in altitude). Looking at how the impact of playing in altitude differs for HAT and LAT, we expect low altitude teams

\footnotetext{
${ }^{12}$ We attribute that to the fact that the FIFA ranking began in 1993, while Paraguay did not participate in the first world cup that the ranking took into account

${ }^{13}$ The ranking in table 1 reflects the team FE, ordered from high to low. It is shown to show some evidence of the consistency of the main results, not yet stated.

${ }^{14}$ Used in official competitions
} 
Table 1: Teams' Ranking according to their performance, ex-post (i.e. with controls)

\begin{tabular}{llllllll}
\hline \hline & OLS1 & OLS1 & OLS2 & OLS2 & OP1 & OP1 & $\begin{array}{l}\text { FIFA } \\
\text { ranking }\end{array}$ \\
\hline Argentina & 1 & 1 & 1 & 1 & 1 & 1 & $6(2)$ \\
Bolivia & 10 & 10 & 10 & 10 & 10 & 10 & $72(9)$ \\
Brasil & 1 & 1 & 1 & 1 & 1 & 1 & $2(1)$ \\
Chile & 6 & 6 & 5 & 6 & 6 & 6 & $37(6)$ \\
Colombia & 4 & 4 & 6 & 4 & 4 & 4 & $24(3)$ \\
Ecuador & 7 & 8 & 7 & 8 & 8 & 8 & $44(7)$ \\
Paraguay & 1 & 1 & 1 & 1 & 1 & 1 & $30(5)$ \\
Peru & 8 & 7 & 8 & 7 & 7 & 7 & $59(8)$ \\
Uruguay & 5 & 5 & 4 & 5 & 5 & 5 & $26(4)$ \\
Venezuela & 9 & 9 & 9 & 9 & 9 & 9 & $81(10)$ \\
\hline FIFA rank & No & Yes & Yes & Yes & No & Yes & \\
year-specific FE & No & No & Yes & Yes & No & No & \\
Colombia as LAT & - & - & No & Yes & - & - & \\
\hline
\end{tabular}

The non-bracketed figures in the last column are the World Ranking; those within the brackets show the relative ranking in South America, so that we have an idea of the distance between one's position in these two rankings.

to be disadvantaged when playing in high altitude compared to high altitude teams which are used to playing in high altitude.

To capture this differential impact of altitude, we construct a new set of variables: $L A T$ is a dummy, which equals 1 when the incumbent team is used to play in low altitude. Just as before, the variable $H A C$ is 1 if the game is played in a high altitude city (Bogota in Colombia, Quito in Ecuador, or La Paz in Bolivia), and 0 otherwise. We then construct the interaction term AltFelt, which takes value 1 only when a team that is not used to play in high altitude $(L A T=1)$ plays in an altitude scenario $(H A C=1) .{ }^{15}$ This second specification is appealing in that the interaction term has a nice interpretation: as its name implies, AltFelt is a subjective measure of altitude. It is coded 1 when the incumbent team plays in altitude and is not used to it, i.e. when it "feels" high altitude. $X_{g}$ is the same set of controls as in the first specification.

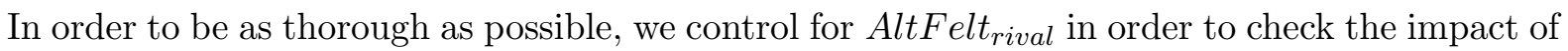
playing against a LAT in a HAT, but this specification is not needed because of the duplication of the data.

The second specification of our model can hence be written in the following way:

$$
\text { Points }_{i n c, g}=\alpha+\beta L A T_{i n c}+\gamma H A C_{g}+\beta^{\text {alt }} \underbrace{L A T_{i n c} * H A C_{g}}_{\text {AltFelt } i n c, g}+\delta X_{g}+u_{i n c, g}
$$

\subsection{Intermediate results}

Estimating the first OLS specification yields our main results, which are displayed in table 2: playing at home implies, on average, 0.8 extra points, which is almost as many points as a

\footnotetext{
${ }^{15}$ Implicitely, in the ex-ante classification, we are assuming that Colombia and Ecuador do not feel the altitude of La Paz, although they are used to play in lower stadiums. We relax this assumption in a following section.
} 
team gets from tying. Compared to Argentina - the reference team - , Bolivia and Ecuador get almost more than an extra point for playing in high altitude stadiums. ${ }^{16}$ The other side of the coin implies that going to altitude to play a game will be more costly when playing against these two teams (around 1.5 fewer points) than when facing Argentina. Overall, Bolivia and

Table 2: First OLS specification: Effects of altitude differing between each team

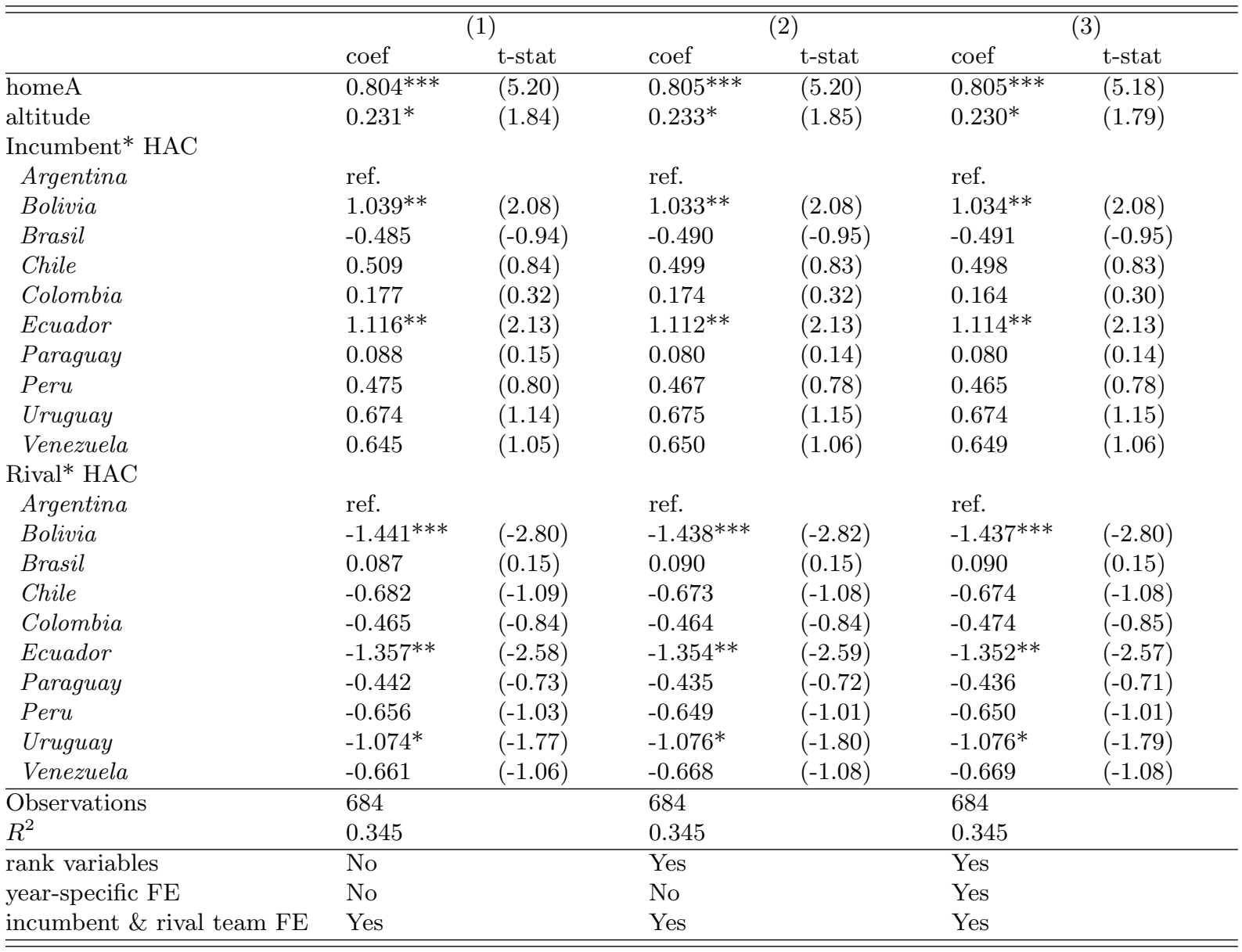

Incumbent and Rival omitted variables are Argentina.

${ }^{*} p<0.1,{ }^{* *} p<0.05,{ }^{* * *} p<0.01$

Ecuador obtain around 2 extra points for playing at home in a high altitude city compared to playing abroad at a sea-level stadium, against a team like Argentina. Going further in the interpretation of these figures, this would imply that if they played two games in Quito or La Paz against Argentina, these HATs would get 4 extra points, meaning they would not lose any game, but instead tie in one and win in the other. Using these results (that only Bolivia and Ecuador can be classified ex post as HATs) for the second OLS specification (see table 3) we obtain the average disadvantage that low altitude teams experience when they play in altitude: they lose, on average, 0.82 points per game (the coefficient corresponding to "altitude felt by

\footnotetext{
${ }^{16}$ As shown in the appendix in equation 2 , the interaction coefficients are diff-in-diff estimates, so that they can be read as the impact of playing in altitude compared to sea-level for a specific team compared to the impact of playing in altitude instead of sea-level for the reference team, here Argentina.
} 
incumbent" in column (2)). Another way to put it is to say that playing against a rival who is not used to high altitude in a high altitude city increases the incumbent's points by 0.88 points (the coefficient corresponding to "altitude felt by rival" in column (2)).

Table 3: Second OLS specification: Effects of altitude differing between LAT and HAT

\begin{tabular}{lllll}
\hline \hline & & & & \\
& coef & t-stat & coef & t-stat \\
\hline home & $0.899^{* * *}$ & $(6.02)$ & $0.800^{* * *}$ & $(5.40)$ \\
altitude (HAC) & -0.086 & $(-1.26)$ & -0.074 & $(-1.06)$ \\
altitude felt by incumbent & $-0.448^{*}$ & $(-1.87)$ & $-0.824^{* * *}$ & $(-3.77)$ \\
altitude felt by rival & $0.548^{* *}$ & $(2.18)$ & $0.879^{* * *}$ & $(3.79)$ \\
\hline Observations & 684 & & 684 & \\
$R^{2}$ & 0.316 & & 0.331 & \\
\hline rank variables & Yes & & Yes & \\
year-specific FE & Yes & Yes & Yes \\
Colombia as a LAT & No & Yes & \\
incumbent \& rival team FE & Yes & &
\end{tabular}

Incumbent and Rival omitted variables are Argentina.

${ }^{*} p<0.1,{ }^{* *} p<0.05,{ }^{* * *} p<0.01$

If on top of that the latter incumbent team is playing home, it gets 0.8 extra points, meaning a global advantage of 1.7 points. If we treat Colombia as a HAT, part of the altitude effect is probably confused with the home advantage, which therefore increases while the "altitude felt" coefficients drop.

\section{Ordered probit and extensions}

Despite that the effect of altitude is robust in its direction and magnitude, there might be reasons to doubt whether the altitude coefficients are not driven by other factors. First of all, the coding of the scores as cardinal rather than ordinal variables may be inflating the altitude coefficients due to some home high altitude victories, which are valued as much as three times a tie. Thus we tackle this issue using an ordered probit framework. Also, we explore whether there are game-specific unobserved conditions that could explain the altitude advantage: for instance, some games may be especially important because their outcome might change the relative ranking between teams, or directly determine who goes to the World Cup or not, and therefore affect the behavior of one team but not the other (for instance through pressure of the home fans, in either direction). Later on, we extend our dataset to cover all qualifiers, and finally we test the effect of altitude on the goal difference rather than on the outcome of the game. None of these alternatives change neither the size nor the sign of the coefficients of interest. ${ }^{17}$

\footnotetext{
${ }^{17}$ We do not report it here, but we have also explored the possibility of imposing a panel structure to the data, and we have also estimated all the linear specifications above changing the outcome variable to be the goal difference. We believe that none of those outputs are worth reporting here as they are uninteresting.
} 


\subsection{Ordered Probit}

As mentioned before, our dependent variable is a categorical dependent variable. It takes on values 0 if the incumbent team loses, 1 if they tie, and 3 if they win. It may be useful to remind the assumption that is intrinsic to such coding when the model is estimated using OLS: because going from losing to tying is worth one point while going from tying to winning is worth two, and the points are here considered as cardinal rather than ordinal, winning is three times better than tying, compared to losing. In other words, the coding of Points $s_{i n c, g}$ does not only imply that winning is a higher achievement than tying, which in turn is better than losing, it also says something about the cardinal value of each outcome. Even though we consider that this assumption is reasonable and that using OLS is therefore appropriate for our purpose, we also estimate a limited-dependent variable model that will take into account the ordinal nature of the dependent variable: the ordered probit model.

As it was the case for the models estimated by OLS, both specifications, allowing the effect of altitude to differ between countries first, and then to differ between LAT and HAT, are shown in tables 8 and 9 in the appendix. The results are unsurprising as Colombia is still an ex-post LAT, while Bolivia and Ecuador are both ex ante and ex post HATs, since they enjoy an altitude advantage with respect of the other countries.

An interesting feature of the ordered probit model is that it allows us to check that although both HATs win more often in altitude, the effect of altitude differs between them. Table 4 shows the counterfactual predicted probabilities had these teams played at the sea-level. Bolivia wins more often playing in high altitude at the expense of losing fewer games, but ties as much as they would in a low altitude city in Bolivia. However, Ecuador wins more often in altitude, but ties less often, and loses less often than in a low altitude stadium in Ecuador (i.e. Guayaquil).

Table 4: Predicted Probabilities for each Outcome, at sea-level and in altitude, for HAT

\begin{tabular}{lllll}
\hline \hline & Altitude & Sea-level & Change & 95\% CI for change \\
\hline Bolivia & & & & \\
$\operatorname{Pr}(\mathrm{y}=0)$ & 0.1320 & 0.6484 & -0.5164 & {$[-0.8077,-0.2251]$} \\
$\operatorname{Pr}(\mathrm{y}=1)$ & 0.2613 & 0.2418 & 0.0196 & {$[-0.0115,0.0507]$} \\
$\operatorname{Pr}(\mathrm{y}=3)$ & 0.6066 & 0.1099 & 0.4968 & {$[0.1746,0.8190]$} \\
\hline Ecuador & & & & \\
$\operatorname{Pr}(\mathrm{y}=0)$ & 0.0457 & 0.3128 & -0.2670 & {$[-0.4609,-0.0732]$} \\
$\operatorname{Pr}(\mathrm{y}=1)$ & 0.1543 & 0.3272 & -0.1729 & {$[-0.1877,-0.1580]$} \\
$\operatorname{Pr}(\mathrm{y}=3)$ & 0.7999 & 0.3601 & 0.4399 & {$[0.1441,0.7357]$} \\
$\operatorname{Colombia}$ & & & & \\
$\operatorname{Pr}(\mathrm{y}=0)$ & 0.0948 & 0.1259 & -0.0310 & {$[-0.1941,0.1321]$} \\
$\operatorname{Pr}(\mathrm{y}=1)$ & 0.2261 & 0.2563 & -0.0302 & {$[-0.0339,-0.0265]$} \\
$\operatorname{Pr}(\mathrm{y}=3)$ & 0.6791 & 0.6179 & 0.0612 & {$[-0.2760,0.3985]$} \\
\hline \hline
\end{tabular}

\subsection{Extensions}

Altitude advantage might be capturing the importance of the game. As mentioned before, some games may be more important than others, for the outcome of one game may 
change the ranking of the teams and determine their participation to the World Cup. More particularly, as the qualifier comes close to its end, one single game between two teams that are very close in the ranking may invert their respective positions and in some cases lead to excluding one in the benefit of the other. Whether because the players are therefore striving more to win, or because the supporters do a better job at cheering their team and/or at influencing the referee (Garicano et al. (2005)), these special circumstances make it harder to get an unbiased estimate of the home advantage, since they can impact in a different way the outcome when the game is played home or away (probably increasing the home bias as it may be that more supporters mobilize to support their team, meaning that the home team has a greater advantage while the away team is even more harmed). Such circumstances could also alter directly our estimation of the impact of altitude if it happens that the home team is systematically a high altitude team. For instance, suppose Ecuador plays the last game of the tournament in Quito (high altitude stadium), against a team of similar or superior quality, which is also competing for the last spot to go to the World Cup. The referee might influence the outcome of the game in favour of the home team and then our previous specifications might have artificially inflated the altitude advantage coefficients. We therefore test a specification where we control for those "important" games and check whether our home and altitude coefficients are robust to the introduction of these particular cases. To do so, we assign to each observation a value $n$ when the incumbent plays for the $n^{\text {th }}$ time in that qualifier. This variable is thus equal to 1 for the first game of the season, and equal to 18 for the last one (or 16 in the case of the 1998 qualifier with only 9 teams). We then generate a dummy for the important days, i.e. for games taking place between day 15 and day 18. Each team has accumulated a certain number of points before they play a game; we use this variable to assign to each team their position in the current ranking before they play. Whenever the incumbent and the rival are close to each other in this ranking, and the game is played at the end of the qualifier, the game is considered to be an important one. In an alternative specification, we consider a game as "important" when on top of being played on an important day, the incumbent team is close to the 5th position, which is decisive since the first 4 teams are prequalified for the World Cup, the 5th has a further chance of qualifying, and the other ones will not participate.

In all specifications the coefficients are either statistically identical in magnitude, or the altitude effect is slightly larger after controlling for the importance of the game in various ways: the home advantage remains around 0.8 points, and the altitude advantage is between 0.8 and 0.85 points. ${ }^{18}$ Interestingly, as shown in the last column of 4.2 , during the last games of the qualifiers, the teams that have a small advantage over their rivals ( 1 point) tend to keep that advantage. In any case, the home advantage and the altitude advantage remain.

Qualifiers before 1994. As mentioned in the introduction, we have leaned toward using only the 4 most recent qualifiers because those tournaments are easily comparable: the tournament

\footnotetext{
${ }^{18}$ Tables 11 and 13 display the estimates when controlling for last games, low difference in rankings, and their interaction, which determines the importance of a game (when the interaction term is 1 ). Table shows the same but with accumulated points rather than the position in the tournament
} 
Table 5: Second OLS specification, controlling for important games (accumulated points)

\begin{tabular}{|c|c|c|c|c|c|c|}
\hline & \multicolumn{2}{|c|}{$(1)$} & \multicolumn{2}{|c|}{$(2)$} & \multicolumn{2}{|c|}{$(3)$} \\
\hline & coef & t-stat & coef & t-stat & coef & t-stat \\
\hline home & $0.789^{* * *}$ & $(5.36)$ & $0.794^{* * *}$ & $(5.38)$ & $0.794^{* * *}$ & $(5.40)$ \\
\hline altitude (HAC) & -0.075 & $(-0.96)$ & -0.071 & $(-0.94)$ & -0.024 & $(-0.32)$ \\
\hline altitude felt by incumbent & $-0.788^{* * *}$ & $(-3.63)$ & $-0.806 * * *$ & $(-3.69)$ & $-0.841^{* * *}$ & $(-3.86)$ \\
\hline altitude felt by rival & $0.865^{* * *}$ & $(3.70)$ & $0.869 * * *$ & $(3.76)$ & $0.850^{* * *}$ & $(3.70)$ \\
\hline last games & -0.007 & $(-0.10)$ & -0.007 & $(-0.14)$ & -0.026 & $(-0.77)$ \\
\hline accumdiff $\leq \mathrm{k}$ & -0.199 & $(-1.60)$ & -0.131 & $(-1.00)$ & -0.031 & $(-0.18)$ \\
\hline last games*accumdiff & -0.040 & $(-0.13)$ & 0.019 & $(0.06)$ & $1.124^{* * *}$ & $(3.87)$ \\
\hline Constant & $1.009 * * *$ & $(10.44)$ & $0.975^{* * *}$ & $(10.73)$ & $0.945^{* * *}$ & $(10.46)$ \\
\hline Observations & 684 & & 684 & & 684 & \\
\hline$R^{2}$ & 0.335 & & 0.332 & & 0.334 & \\
\hline accumdiff $\leq \mathrm{k}$ & $k=5$ & & $k=3$ & & $k=1$ & \\
\hline Colombia as a LAT & Yes & & Yes & & Yes & \\
\hline year-specific FE & No & & No & & No & \\
\hline incumbent \& rival team FE & Yes & & Yes & & Yes & \\
\hline
\end{tabular}

Incumbent and Rival omitted variables are Argentina.

${ }^{*} p<0.1,{ }^{* *} p<0.05, * * * p<0.01$

structure was kept constant, including the points awarded to the winner of a game, the number of games played, and most importantly all teams played against each other (the only exception is the 1998 qualifiers in which Brasil did not participate). However, in this section we include all the games played since there were qualifiers (since 1954). Despite that in all those new games, the points awarded to the winner of the game were 2 points, we still assign 3 points to the winner, in order to keep the figures comparable. Table 6 shows that the results are unchanged, except for the fact that all effects are milder. One relevant institutional change at the FIFA level could explain this pattern: until the 1994 qualifiers, all games were played in a relatively short time span (between one 30 and 45 days) during the boreal summer, during the players' holidays. Thus players would have between a few weeks or even one month to train in their national teams. Therefore they had enough time to do the proposed medical acclimatization to high altitudes. Conversely, since the 1998 qualifiers, games were played during the regular season and clubs only had to loan their players 5 days before any official game, not leaving enough time for the two-week-acclimatization required according to the specialists. ${ }^{19}$

\section{Conclusion}

The structure of professional sports such as football allows us to document predictions from the theory of rank-order tournaments (Lazear and Rosen (1981), Che and Gale (2003) and others). In particular we prove that, in an environment of heterogeneous teams, playing in high altitude constitutes a handicap, which increases the tournaments efficiency by making the contest more

\footnotetext{
${ }^{19} \mathrm{~A}$ complementary argument is that in the older tournaments, travelling by plane required more stopovers. In such case, there could be unobservables affecting the regression estimates. For instance, Bolivia playing against Argentina in La Paz after playing against Colombia in Bogota could have meant more than 20 hours travelling for the Bolivian team.
} 
Table 6: Second OLS specification: Effects of altitude differing between LAT and HAT, from 1954 to 1994

\begin{tabular}{lllll}
\hline \hline & \multicolumn{2}{c}{$(1)$} & & $(2)$ \\
& coef & t-stat & coef & t-stat \\
\hline home & $0.855^{* * *}$ & $(4.85)$ & $0.768^{* * *}$ & $(4.98)$ \\
altitude (HAC) & -0.116 & $(-0.71)$ & 0.024 & $(0.22)$ \\
altitude felt by incumbent & -0.014 & $(-0.05)$ & $-0.614^{* *}$ & $(-2.10)$ \\
altitude felt by rival & 0.231 & $(0.70)$ & $0.560^{*}$ & $(1.80)$ \\
\hline Observations & 404 & & 404 & \\
$R^{2}$ & 0.440 & & 0.451 & \\
\hline year-specific FE & Yes & Yes & \\
Colombia as a LAT & No & Yes & Yes \\
incumbent \& rival team FE & Yes & &
\end{tabular}

Incumbent and Rival omitted dummies are Argentina

${ }^{*} p<0.1,{ }^{* *} p<0.05,{ }^{* * *} p<0.01$

competitive. As intermediate steps, we have identified three national teams which may ex-ante have an advantage (Colombia, Ecuador and Bolivia) and we show that only Ecuador and Bolivia benefit from this altitude advantage. Due to the 1994 reform of the tournament structure, the national teams do not have the opportunity to acclimatize, therefore only the ex-ante high altitude teams may have this exogenous advantage. We provide evidence that if high altitude stadiums were banned, Ecuador and Bolivia would consistently be among the three worst teams in South America (with Venezuela). These two teams win more than half of their games in their high altitude home stadiums due to altitude, which shows to what extent altitude is an extra advantage for Ecuador and Bolivia- two of the worst teams of the tournament- and hence a handicap for the best teams.

How the altitude advantage/disadvantage might boost competitiveness is almost straightforward: on the one hand, the teams who suffer from the altitude disadvantage have to strive more to qualify for the World Cup; on the other hand, the altitude advantage allows the other teams, which might not be able to qualify if there was no bias in their favor, to have better chances of going to the World Cup, hence inducing higher efforts from them too. This was the case for Ecuador in the 2002 and 2006 World Cups. It is noteworthy that despite the public attempts to ban the high altitude scenarios, FIFA's most recent change in the South American contest actually led to increasing the handicap: by changing the tournament structure in 1994, they have made it impossible for the players to acclimatize properly since their teams are not allowed to use them more than 5 days in advance.

Finally, all these results, which are consistent with Lazear and Rosen (1981), Che and Gale (2003), Knoeber and Thurman (1994) and others, have been estimated using a publicly available data but exploiting three identification avenues which have been unexplored until now: 1) the changes of host cities (and so of their altitudes) within a country, 2) the variation across teams in adaptation to altitude, and 3) the tournament structure, which makes each couple of teams face each other once home and once away.

In sum, we exploit a public dataset in a novel way to show that (1) playing football in altitude 
stadiums makes the non-acclimatized team less likely to win, (2) that this altitude advantage can be separated from the home bias, (3) that this advantage can be thought of as a handicap, and (4) that it may be welfare improving, in the sense that it makes the South American Qualifying tournaments more competitive, and therefore may induce higher effort from all teams. Along these lines, leaving aside medical considerations, we believe that high altitude stadiums should not be banned from international competitions as they make the tournament more competitive, incentivize the teams to put more effort, and therefore render the tournament interesting until the last game is over.

\section{References}

Brutsaert, T., H. Spielvogel, R. Soria, M. Araoz, E. Caceres, G. Buzenet, M. Villena, M. Paz Zamora, and E. Vargas (2008). Performance of Altitude Acclimatized and Non-Acclimatized Professional Football (Soccer) Players at 3,600 M. Journal of Exercise Physiology.

Che, Y. and I. Gale (2003). Optimal design of research contests. American Economic Review.

Chumacero, R. A. (2009, July). Altitude or Hot Air? Journal of Sports Economics 10(6), 619-638.

Eugster, M., J. Gertheiss, and S. Kaiser (2011). Having the Second Leg at Home-Advantage in the UEFA Champions League Knockout Phase? Journal of Quantitative Analysis in Sports.

Garicano, L., I. Palacios-Huerta, and C. Prendergast (2005, May). Favoritism Under Social Pressure. Review of Economics and Statistics 87(2), 208-216.

Karlis, D. and I. Ntzoufras (2003). Analysis of sports data by using bivariate Poisson models. Journal of the Royal Statistical Society.

Knoeber, C. and W. Thurman (1994). Testing the theory of tournaments: An empirical analysis of broiler production. Journal of Labor Economics.

Lazear, E. and S. Rosen (1981). Rank-order tournaments as optimum labor contracts. The Journal of Political Economy.

Levine, B. D., J. Stray-Gundersen, and R. D. Mehta (2008, August). Effect of altitude on football performance. Scandinavian journal of medicine 85 science in sports 18 Suppl 1, $76-84$.

Levy, A. and T. Vukina (2004, April). The League Composition Effect in Tournaments with Heterogeneous Players: An Empirical Analysis of Broiler Contracts. Journal of Labor Economics 22(2), 353-377.

McLaughlin, K. J. K. (1988). Aspects of tournament models: a survey. Research in labor economics 9, 225- 256 . 
McSharry, P. E. (2007, December). Effect of altitude on physiological performance: a statistical analysis using results of international football games. BMJ (Clinical research ed.) 335(7633), $1278-81$.

Pettersson-Lidbom, P. and M. Priks (2010). Behavior under social pressure: Empty Italian stadiums and referee bias. Economics Letters.

Pollard, R. (1986). Home advantage in soccer: a retrospective analysis. Journal of Sports Sciences.

Szymanski, S. (2003). The economic design of sporting contests. Journal of Economic Literature.

Williams, T. (2011). The Effects of Altitude on Soccer Match Outcomes. sloansportsconference.com.

\section{Appendix}

\subsection{Identification strategy}

The identification of our model comes from two sources: the exogenous variation in the data, with every team playing sometimes at sea-level, sometimes at high altitude levels, and from converting each game in two observations, which allows us to disentangle the altitude impact from the so-called home bias.

The latter is given in equation (1) by the average change in the incumbent's points when playing home and away, ceteris paribus, i.e. holding Inc, $X$ (which includes the rival team, FIFA ranks for the two teams, and some other variables in other specifications), and $H A C$ fixed:

$$
\delta^{\text {Home }}=E\left[\text { Points }_{\text {inc,g }} \mid X, H A C, \text { inc }, \text { Home }=1\right]-E\left[\text { Points }_{\text {inc }, g} \mid X, H A C, \text { inc }, \text { Home }=0\right]
$$

Ideally, we would observe all games between the incumbent and its rival twice at the same altitude level, once in the incumbent's country $($ Home $=1)$ and once in the rival's $($ Home $=0)$. Unfortunately we do not have these observations for all teams (e.g. when Bolivia plays against a sea-level team, Home and Away mean two different altitude levels), but as long as we do have such observations, and we do for almost all teams, the Home coefficient is identified.

The impact of altitude is given by the average change in the incumbent's points when playing in high altitude compared to playing at sea-level, ceteris paribus, i.e. holding Inc, $X$, and Home fixed:

$$
\gamma=E\left[\text { Points }_{i n c, g} \mid H A C=1, X, \text { inc }, \text { Home }\right]-E\left[\text { Points }_{\text {inc }, g} \mid H A C=0, X, \text { inc }, \text { Home }\right]
$$


Again, some games between the incumbent and a rival are played once in a HAC and once in a LAC within one country (e.g. in Ecuador and Colombia), so that this coefficient is identified. Still, it is totally uninformative since $H A C$ takes only one value per game, unlike Home, which varies across the two observations of one game. Thus, $H A C$ is estimated to have the same

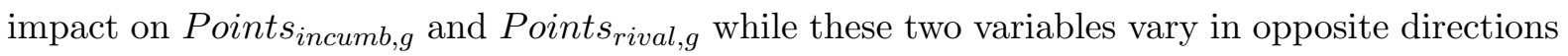
(except in the case of a draw, when Points incumb,$g=$ Points $_{\text {rival }, g}=1$ ). This is not an issue as we are not interested in the average impact of $H A C$, but rather in how $H A C$ affects differentially each team, which we estimate using the interaction terms.

One way of getting a precise estimate of the impact of playing in altitude for $I n c_{i}$ against Rival $_{j}$ would consist in adding interactions $\operatorname{Inc} *$ Rival $* H A C$, but then the model would be overspecified, so that we prefer double to triple interactions, even though our estimates will underestimate the altitude bias when the incumbent is a sea-level team and encounters a high altitude rival in a high altitude city.

\subsection{Ordered Probit}

The central idea is that there is some latent continuous metric underlying the ordinal dependent variable, with thresholds partitioning the real universe of the variable into a series of intervals corresponding to the various ordinal categories. So there exists a latent continuous variable $y^{*}$ that is a linear function of the same vector of explanatory variables as in Equation 1.

$$
y_{i, g}^{*}=X_{i, g} \beta+u_{i d}
$$

where $u_{i d}$ is a disturbance term having a standard Normal distribution, still clustered at the game level. Now our observed ordinal variable takes on value $j, j=0,1,3$ according to the following scheme:

$$
\text { Points }_{i n c_{i}, g}=j \Leftrightarrow \mu_{j-1}<y_{i, g}^{*} \leq \mu_{j},
$$

where $\mu_{-1}=-\infty$ and $\mu_{3}=+\infty$. We then use the cumulative distribution function of the Normal distribution to derive the probability of each ordinal outcome $P\left(\right.$ Points $\left._{\text {inc }_{i}, g}=j\right)=$ $\Phi\left(\mu_{j}-X_{i, g} \beta\right)-\Phi\left(\mu_{j-1}-X_{i, g} \beta\right)$, for $j=0,1,3$. This model is then estimated using maximum likelihood estimation, but the latter does not yield one unique solution: there is no unique combination of the $\mu$ thresholds and the $\beta$ parameters that maximizes the fit to the data. It is therefore necessary to impose two identification constraints, one upon one $\mu$ term, such as $\mu_{0}$, the other upon the standard deviation term $\sigma$ (standard practice is to set it equal to 1 ). These identifying assumptions are to a large extent arbitrary, and another solution would consist in re-defining the latent variable $y_{i, g}^{*}$ as a meaningful quantity, and define the thresholds in terms of this new metric. In our case, an intuitive candidate for the latent variable would be the goal 
difference between team $\mathrm{A}$ and team $\mathrm{B}$. In this case,

$$
y_{i, g}^{*}=\left\{\begin{array}{l}
0 \text { if } \text { goal }^{A}-\text { goal }^{B} \leq-1 \\
1 \text { if }-1<\text { goal }^{A}-\text { goal }^{B} \leq 0 \\
3 \text { if } 0<\text { goal }^{A}-\text { goal }^{B}
\end{array}\right.
$$

The cut-points are then given by: $\mu_{0}=-1 ; \mu_{1}=0$. As the latent variable is supposed to be continuous, and the goal difference is clearly discrete, we will use the standard constraints, but the interpretation of the results is clearer when thinking of the latent variable being the latter. 


\subsection{Tables and Figures}

Table 7: Summary statistics on Home vs Away games by altitude level: Number of games Lost/Tied/Won

\begin{tabular}{|c|c|c|c|c|c|c|c|c|c|c|c|c|c|c|c|c|}
\hline \multirow{3}{*}{$\begin{array}{l}\text { Team } \\
\text { Outcome }\end{array}$} & \multicolumn{6}{|c|}{ Home } & \multicolumn{6}{|c|}{ Away } & \multirow{2}{*}{\multicolumn{3}{|c|}{ Total }} & \\
\hline & \multicolumn{3}{|c|}{ sea-level } & \multicolumn{3}{|c|}{ altitude } & \multicolumn{3}{|c|}{ sea-level } & \multicolumn{3}{|c|}{ altitude } & & & & \\
\hline & $\mathrm{L}$ & $\mathrm{T}$ & $\mathrm{W}$ & $\mathrm{L}$ & $\mathrm{T}$ & $\mathrm{W}$ & $\mathrm{L}$ & $\mathrm{T}$ & $\mathrm{W}$ & $\mathrm{L}$ & $\mathrm{T}$ & $\mathrm{W}$ & $\mathrm{L}$ & $\mathrm{T}$ & $\mathrm{W}$ & \\
\hline Argentina & 1 & 9 & 25 & - & - & - & 6 & 8 & 11 & 6 & 1 & 3 & 13 & 18 & 39 & 70 \\
\hline Bolivia & - & - & - & 7 & 12 & 16 & 26 & 4 & 0 & 5 & 0 & 0 & 38 & 16 & 16 & 70 \\
\hline Brasil & 0 & 8 & 19 & - & - & - & 6 & 5 & 8 & 4 & 4 & 0 & 10 & 17 & 27 & 54 \\
\hline Chile & 8 & 10 & 17 & - & - & - & 15 & 5 & 6 & 5 & 2 & 2 & 28 & 17 & 25 & 70 \\
\hline Colombia & 5 & 3 & 12 & 5 & 3 & 7 & 10 & 10 & 7 & 2 & 5 & 1 & 22 & 21 & 27 & 70 \\
\hline Ecuador & 0 & 0 & 2 & 4 & 8 & 21 & 20 & 7 & 3 & 1 & 1 & 3 & 25 & 16 & 29 & 70 \\
\hline Paraguay & 5 & 3 & 27 & - & - & - & 12 & 6 & 7 & 5 & 3 & 2 & 22 & 12 & 36 & 70 \\
\hline Peru & 9 & 12 & 14 & - & - & - & 20 & 4 & 3 & 5 & 2 & 1 & 34 & 18 & 18 & 70 \\
\hline Uruguay & 6 & 9 & 20 & - & - & - & 14 & 8 & 3 & 3 & 5 & 2 & 23 & 22 & 25 & 70 \\
\hline Venezuela & 17 & 7 & 11 & - & - & - & 18 & 4 & 3 & 8 & 0 & 2 & 43 & 11 & 16 & 70 \\
\hline
\end{tabular}


Table 8: First Ordered Probit specification: Effects of altitude differing between each team

\begin{tabular}{|c|c|c|c|c|}
\hline & \multicolumn{2}{|c|}{ (1) } & \multicolumn{2}{|c|}{ (2) } \\
\hline & coef & t-stat & coef & t-stat \\
\hline home & $0.848^{* * *}$ & $(4.99)$ & $0.851^{* * *}$ & $(4.99)$ \\
\hline altitude (HAC) & -0.000 & . & -0.000 & . \\
\hline \multicolumn{5}{|l|}{ Incumbent* HAC } \\
\hline Argentina & ref. & & ref. & \\
\hline Bolivia & $1.637^{* * *}$ & $(2.83)$ & $1.630 * * *$ & $(2.83)$ \\
\hline Brasil & -0.159 & $(-0.27)$ & -0.164 & $(-0.28)$ \\
\hline Chile & 0.704 & $(1.11)$ & 0.695 & $(1.10)$ \\
\hline Colombia & 0.384 & $(0.69)$ & 0.380 & $(0.69)$ \\
\hline Ecuador & $1.356^{* *}$ & $(2.43)$ & $1.352^{* *}$ & $(2.43)$ \\
\hline Paraguay & 0.293 & $(0.48)$ & 0.290 & $(0.48)$ \\
\hline Peru & 0.692 & $(1.05)$ & 0.689 & $(1.04)$ \\
\hline Uruguay & $0.977^{*}$ & (1.68) & $0.975^{*}$ & (1.69) \\
\hline Venezuela & 0.705 & $(0.96)$ & 0.709 & $(0.97)$ \\
\hline \multicolumn{5}{|l|}{ Rival* HAC } \\
\hline Argentina & ref. & & ref. & \\
\hline Bolivia & $-1.637^{* * *}$ & $(-2.83)$ & $-1.630 * * *$ & $(-2.83)$ \\
\hline Brasil & 0.159 & $(0.27)$ & 0.164 & $(0.28)$ \\
\hline Chile & -0.704 & $(-1.11)$ & -0.695 & $(-1.10)$ \\
\hline Colombia & -0.384 & $(-0.69)$ & -0.380 & $(-0.69)$ \\
\hline Ecuador & $-1.356^{* *}$ & $(-2.43)$ & $-1.352^{* *}$ & $(-2.43)$ \\
\hline Paraguay & -0.293 & $(-0.48)$ & -0.290 & $(-0.48)$ \\
\hline Peru & -0.692 & $(-1.05)$ & -0.689 & $(-1.04)$ \\
\hline Uruguay & $-0.977^{*}$ & $(-1.68)$ & $-0.975^{*}$ & $(-1.69)$ \\
\hline Venezuela & -0.705 & $(-0.96)$ & -0.709 & $(-0.97)$ \\
\hline \multicolumn{5}{|c|}{ Incumbent dummies } \\
\hline Argentina & ref. & & ref. & \\
\hline Bolivia & $-1.843^{* * *}$ & $(-5.78)$ & $-1.738^{* * *}$ & $(-4.84)$ \\
\hline Brasil & -0.078 & $(-0.36)$ & -0.083 & $(-0.38)$ \\
\hline Chile & $-0.725^{* * *}$ & $(-3.59)$ & $-0.667 * * *$ & $(-2.79)$ \\
\hline Colombia & $-0.450 * *$ & $(-2.08)$ & $-0.421^{*}$ & $(-1.93)$ \\
\hline Ecuador & $-1.012^{* * *}$ & $(-4.07)$ & $-0.950 * * *$ & $(-3.49)$ \\
\hline Paraguay & -0.266 & $(-1.33)$ & -0.234 & $(-1.10)$ \\
\hline Peru & $-0.993^{* * *}$ & $(-5.12)$ & $-0.904^{* * *}$ & $(-3.53)$ \\
\hline Uruguay & $-0.646 * * *$ & $(-3.42)$ & $-0.607 * * *$ & $(-2.98)$ \\
\hline Venezuela & $-1.249 * * *$ & $(-5.93)$ & $-1.121^{* * *}$ & $(-3.51)$ \\
\hline \multicolumn{5}{|l|}{ Rival dummies } \\
\hline Argentina & ref. & & ref. & \\
\hline Bolivia & $1.843^{* * *}$ & $(5.78)$ & $1.738^{* * *}$ & $(4.84)$ \\
\hline Brasil & 0.078 & $(0.36)$ & 0.083 & $(0.38)$ \\
\hline Chile & $0.725^{* * *}$ & $(3.59)$ & $0.667^{* * *}$ & $(2.79)$ \\
\hline Colombia & $0.450^{* *}$ & $(2.08)$ & $0.421^{*}$ & (1.93) \\
\hline Ecuador & $1.012^{* * *}$ & $(4.07)$ & $0.950 * * *$ & $(3.49)$ \\
\hline Paraguay & 0.266 & $(1.33)$ & 0.234 & $(1.10)$ \\
\hline Peru & $0.993^{* * *}$ & $(5.12)$ & $0.904^{* * *}$ & $(3.53)$ \\
\hline Uruguay & $0.646^{* * *}$ & $(3.42)$ & $0.607^{* * *}$ & $(2.98)$ \\
\hline Venezuela & $1.249 * * *$ & $(5.93)$ & $1.121^{* * *}$ & $(3.51)$ \\
\hline cut1 & 0.001 & $(0.01)$ & 0.002 & $(0.03)$ \\
\hline cut2 & $0.847^{* * *}$ & $(8.61)$ & $0.849^{* * *}$ & $(8.60)$ \\
\hline Observations & 684 & & 684 & \\
\hline Pseudo $R^{2}$ & 0.196 & & 0.196 & \\
\hline rank variables & No & & Yes & \\
\hline year-specific FE & No & & No & \\
\hline
\end{tabular}

${ }^{*} p<0.1,{ }^{* *} p<0.05,{ }^{* * *} p<0.01$ 
Table 9: Second Ordered Probit specification: Effects of altitude differing between LAT and HAT

\begin{tabular}{|c|c|c|c|c|}
\hline & \multicolumn{2}{|c|}{ (1) } & \multicolumn{2}{|c|}{$(2)$} \\
\hline & coef & t-stat & coef & t-stat \\
\hline home & $0.949^{* * *}$ & $(5.83)$ & $0.838^{* * *}$ & $(5.23)$ \\
\hline altitude (HAC) & -0.000 & $(-0.00)$ & -0.000 & . \\
\hline \multicolumn{5}{|l|}{ Incumbent dummies } \\
\hline Argentina & ref. & & ref. & \\
\hline Bolivia & $-1.213^{* * *}$ & $(-4.31)$ & $-1.542^{* * *}$ & $(-5.04)$ \\
\hline Brasil & -0.100 & $(-0.51)$ & -0.109 & $(-0.55)$ \\
\hline Chile & $-0.569^{* *}$ & $(-2.53)$ & $-0.567^{* *}$ & $(-2.50)$ \\
\hline Colombia & $-0.555^{* * *}$ & $(-2.73)$ & $-0.364^{*}$ & $(-1.91)$ \\
\hline Ecuador & $-0.665^{* * *}$ & $(-2.81)$ & $-0.943^{* * *}$ & $(-3.73)$ \\
\hline Paraguay & -0.191 & $(-0.94)$ & -0.192 & $(-0.96)$ \\
\hline Peru & $-0.798 * * *$ & $(-3.20)$ & $-0.807 * * *$ & $(-3.24)$ \\
\hline Uruguay & $-0.460 * *$ & $(-2.40)$ & $-0.461^{* *}$ & $(-2.40)$ \\
\hline Venezuela & $-1.004^{* * *}$ & $(-3.20)$ & $-1.012^{* * *}$ & $(-3.20)$ \\
\hline \multicolumn{5}{|l|}{ Rival dummies } \\
\hline Argentina & ref. & & ref. & \\
\hline Bolivia & $1.213^{* * *}$ & $(4.31)$ & $1.542^{* * *}$ & $(5.04)$ \\
\hline Brasil & 0.100 & $(0.51)$ & 0.109 & $(0.55)$ \\
\hline Chile & $0.569^{* *}$ & $(2.53)$ & $0.567^{* *}$ & $(2.50)$ \\
\hline Colombia & $0.555^{* * *}$ & $(2.73)$ & $0.364^{*}$ & $(1.91)$ \\
\hline Ecuador & $0.665^{* * *}$ & $(2.81)$ & $0.943^{* * *}$ & $(3.73)$ \\
\hline Paraguay & 0.191 & $(0.94)$ & 0.192 & $(0.96)$ \\
\hline Peru & $0.798^{* * *}$ & $(3.20)$ & $0.807^{* * *}$ & $(3.24)$ \\
\hline Uruguay & $0.460^{* *}$ & $(2.40)$ & $0.461^{* *}$ & $(2.40)$ \\
\hline Venezuela & $1.004^{* * *}$ & $(3.20)$ & $1.012^{* * *}$ & $(3.20)$ \\
\hline altitude felt by incumbent & $-0.545^{* *}$ & $(-2.10)$ & $-1.008^{* * *}$ & $(-3.77)$ \\
\hline altitude felt by rival & $0.545^{* *}$ & $(2.10)$ & $1.008^{* * *}$ & $(3.77)$ \\
\hline cut1 & 0.066 & $(0.77)$ & 0.003 & $(0.03)$ \\
\hline cut2 & $0.883^{* * *}$ & $(9.28)$ & $0.835^{* * *}$ & $(8.82)$ \\
\hline$\overline{\text { Observations }}$ & 684 & & 684 & \\
\hline Pseudo $R^{2}$ & 0.176 & & 0.188 & \\
\hline rank variables & Yes & & Yes & \\
\hline year-specific FE & No & & No & \\
\hline Colombia as a LAT & No & & Yes & \\
\hline
\end{tabular}

${ }^{*} p<0.1,{ }^{* *} p<0.05,{ }^{* * *} p<0.01$ 
Table 10: First OLS specification: Effects of altitude differing between each team, from 1954 to 1994

\begin{tabular}{|c|c|c|c|c|}
\hline & \multicolumn{2}{|c|}{ (1) } & \multicolumn{2}{|c|}{ (2) } \\
\hline & coef & t-stat & coef & t-stat \\
\hline home & $0.785^{* * *}$ & $(4.51)$ & $0.785^{* * *}$ & $(4.44)$ \\
\hline altitude (HAC) & 0.208 & $(1.01)$ & 0.185 & $(0.85)$ \\
\hline \multicolumn{5}{|l|}{ Incumbent* $\mathrm{HAC}$} \\
\hline Argentina & ref. & & ref. & \\
\hline Bolivia & 0.243 & $(0.32)$ & 0.240 & $(0.31)$ \\
\hline Brasil & -0.675 & $(-0.69)$ & -0.629 & $(-0.64)$ \\
\hline Chile & $-1.489^{* *}$ & $(-2.01)$ & $-1.489^{* *}$ & $(-1.97)$ \\
\hline Colombia & -1.194 & $(-1.57)$ & -1.186 & $(-1.52)$ \\
\hline Ecuador & -1.093 & $(-1.43)$ & -1.066 & $(-1.37)$ \\
\hline Paraguay & 0.737 & $(0.85)$ & 0.758 & $(0.85)$ \\
\hline Peru & $-1.325^{*}$ & $(-1.86)$ & $-1.315^{*}$ & $(-1.81)$ \\
\hline Uruguay & -1.023 & $(-1.39)$ & -1.005 & $(-1.34)$ \\
\hline Venezuela & -0.764 & $(-1.06)$ & -0.735 & $(-0.99)$ \\
\hline \multicolumn{5}{|l|}{ Rival* HAC } \\
\hline Argentina & ref. & & ref. & \\
\hline Bolivia & -0.440 & $(-0.59)$ & -0.443 & $(-0.59)$ \\
\hline Brasil & 0.567 & $(0.62)$ & 0.614 & $(0.66)$ \\
\hline Chile & 1.008 & $(1.38)$ & 1.008 & $(1.38)$ \\
\hline Colombia & 0.749 & $(1.03)$ & 0.757 & $(1.03)$ \\
\hline Ecuador & 0.763 & $(0.99)$ & 0.789 & $(1.01)$ \\
\hline Paraguay & -0.528 & $(-0.63)$ & -0.508 & $(-0.60)$ \\
\hline Peru & 1.176 & $(1.59)$ & 1.185 & $(1.59)$ \\
\hline Uruguay & 0.675 & $(0.92)$ & 0.693 & $(0.94)$ \\
\hline Venezuela & 0.754 & $(1.04)$ & 0.783 & $(1.07)$ \\
\hline Observations & 404 & & 404 & \\
\hline$R^{2}$ & 0.496 & & 0.497 & \\
\hline year-specific FE & No & & Yes & \\
\hline incumbent and rival $\mathrm{FE}$ & Yes & & Yes & \\
\hline
\end{tabular}

Incumbent and Rival omitted dummies are Argentina

${ }^{*} p<0.1,{ }^{* *} p<0.05,{ }^{* * *} p<0.01$ 
Table 11: First OLS specification, controlling for important games

\begin{tabular}{|c|c|c|c|c|c|c|}
\hline & \multicolumn{2}{|c|}{ (1) } & \multicolumn{2}{|c|}{$\overline{(2)}$} & \multicolumn{2}{|c|}{$(3)$} \\
\hline & coef & t-stat & coef & t-stat & coef & t-stat \\
\hline home & $0.806^{* * *}$ & $(5.20)$ & $0.815^{* * *}$ & $(5.25)$ & $0.805^{* * *}$ & $(5.20)$ \\
\hline altitude (HAC) & $0.240^{*}$ & $(1.92)$ & $0.218^{*}$ & $(1.73)$ & $0.240^{*}$ & $(1.88)$ \\
\hline \multicolumn{7}{|l|}{ Incumbent* HAC } \\
\hline Argentina & ref. & & ref. & & ref. & \\
\hline Bolivia & $1.002^{* *}$ & $(1.98)$ & $0.996^{* *}$ & $(1.97)$ & $1.040 * *$ & $(2.06)$ \\
\hline Brasil & -0.474 & $(-0.91)$ & -0.478 & $(-0.92)$ & -0.488 & $(-0.94)$ \\
\hline Chile & 0.506 & $(0.84)$ & 0.516 & $(0.85)$ & 0.511 & $(0.84)$ \\
\hline Colombia & 0.163 & $(0.30)$ & 0.171 & $(0.31)$ & 0.173 & $(0.32)$ \\
\hline Ecuador & $1.081^{* *}$ & $(2.04)$ & $1.034^{*}$ & $(1.95)$ & $1.108^{* *}$ & $(2.09)$ \\
\hline Paraguay & 0.078 & $(0.13)$ & 0.070 & $(0.12)$ & 0.085 & $(0.14)$ \\
\hline Peru & 0.476 & $(0.81)$ & 0.464 & $(0.79)$ & 0.477 & $(0.80)$ \\
\hline Uruguay & 0.647 & $(1.10)$ & 0.646 & $(1.10)$ & 0.673 & (1.13) \\
\hline Venezuela & 0.625 & $(1.00)$ & 0.632 & $(1.01)$ & 0.647 & $(1.05)$ \\
\hline \multicolumn{7}{|l|}{ Rival* HAC } \\
\hline Argentina & ref. & & ref. & & ref. & \\
\hline Bolivia & $-1.427 * * *$ & $(-2.80)$ & $-1.387 * * *$ & $(-2.73)$ & $-1.443^{* * *}$ & $(-2.81)$ \\
\hline Brasil & 0.103 & $(0.18)$ & 0.136 & $(0.23)$ & 0.082 & $(0.14)$ \\
\hline Chile & -0.690 & $(-1.11)$ & -0.654 & $(-1.05)$ & -0.687 & $(-1.10)$ \\
\hline Colombia & -0.476 & $(-0.87)$ & -0.431 & $(-0.78)$ & -0.471 & $(-0.85)$ \\
\hline Ecuador & $-1.346^{* *}$ & $(-2.58)$ & $-1.323^{* *}$ & $(-2.54)$ & $-1.358^{* *}$ & $(-2.58)$ \\
\hline Paraguay & -0.403 & $(-0.67)$ & -0.381 & $(-0.63)$ & -0.443 & $(-0.73)$ \\
\hline Peru & -0.732 & $(-1.16)$ & -0.731 & $(-1.16)$ & -0.664 & $(-1.04)$ \\
\hline Uruguay & $-1.099 *$ & $(-1.84)$ & $-1.038^{*}$ & $(-1.74)$ & $-1.078^{*}$ & $(-1.78)$ \\
\hline Venezuela & -0.661 & $(-1.06)$ & -0.619 & $(-0.98)$ & -0.666 & $(-1.07)$ \\
\hline \multicolumn{7}{|l|}{ Incumbent dummies } \\
\hline Argentina & ref. & & ref. & & ref. & \\
\hline Bolivia & $-1.344^{* * *}$ & $(-7.73)$ & $-1.346^{* * *}$ & $(-7.72)$ & $-1.342^{* * *}$ & $(-7.71)$ \\
\hline Brasil & -0.035 & $(-0.17)$ & -0.035 & $(-0.17)$ & -0.022 & $(-0.11)$ \\
\hline Chile & $-0.642^{* * *}$ & $(-3.31)$ & $-0.640 * * *$ & $(-3.32)$ & $-0.612^{* * *}$ & $(-3.16)$ \\
\hline Colombia & $-0.410^{*}$ & $(-1.96)$ & $-0.407^{*}$ & $(-1.93)$ & $-0.398^{*}$ & $(-1.90)$ \\
\hline Ecuador & $-0.863^{* * *}$ & $(-4.19)$ & $-0.837^{* * *}$ & $(-4.09)$ & $-0.855^{* * *}$ & $(-4.17)$ \\
\hline Paraguay & -0.192 & $(-1.03)$ & -0.189 & $(-1.01)$ & -0.189 & $(-1.01)$ \\
\hline Peru & $-0.893^{* * *}$ & $(-5.05)$ & $-0.886 * * *$ & $(-5.04)$ & $-0.873^{* * *}$ & $(-4.97)$ \\
\hline Uruguay & $-0.612^{* * *}$ & $(-3.23)$ & $-0.600 * * *$ & $(-3.25)$ & $-0.576^{* * *}$ & $(-3.16)$ \\
\hline Venezuela & $-1.069 * * *$ & $(-6.05)$ & $-1.069 * * *$ & $(-6.04)$ & $-1.047^{* * *}$ & $(-5.96)$ \\
\hline \multicolumn{7}{|l|}{ Rival dummies } \\
\hline Argentina & ref. & & ref. & & ref. & \\
\hline Bolivia & $1.539 * * *$ & $(7.89)$ & $1.518^{* * *}$ & $(7.93)$ & $1.503^{* * *}$ & $(7.93)$ \\
\hline Brasil & 0.039 & $(0.23)$ & 0.035 & $(0.21)$ & 0.028 & $(0.17)$ \\
\hline Chile & $0.685^{* * *}$ & $(3.89)$ & $0.679 * * *$ & $(3.89)$ & $0.657^{* * *}$ & $(3.71)$ \\
\hline Colombia & $0.434^{* *}$ & $(2.16)$ & $0.418^{* *}$ & $(2.09)$ & $0.417^{* *}$ & $(2.07)$ \\
\hline Ecuador & $0.956^{* * *}$ & $(4.44)$ & $0.947 * * *$ & $(4.39)$ & $0.935^{* * *}$ & $(4.35)$ \\
\hline Paraguay & $0.361^{* *}$ & $(2.04)$ & $0.356^{* *}$ & $(2.02)$ & $0.347^{* *}$ & (1.98) \\
\hline Peru & $0.942^{* * *}$ & $(5.53)$ & $0.932^{* * *}$ & $(5.57)$ & $0.903^{* * *}$ & $(5.44)$ \\
\hline Uruguay & $0.596^{* * *}$ & $(3.53)$ & $0.589^{* * *}$ & $(3.52)$ & $0.579^{* * *}$ & $(3.47)$ \\
\hline Venezuela & $1.205^{* * *}$ & $(7.04)$ & $1.193^{* * *}$ & $(7.03)$ & $1.166^{* * *}$ & $(7.01)$ \\
\hline last games & 0.009 & $(0.11)$ & 0.018 & $(0.29)$ & 0.010 & $(0.23)$ \\
\hline $\operatorname{diff}<\mathrm{k}$ & 0.145 & $(1.04)$ & 0.186 & $(1.17)$ & 0.034 & $(0.13)$ \\
\hline$($ last games $) *(\operatorname{diff} \leq \mathrm{k})$ & 0.012 & $(0.04)$ & -0.024 & $(-0.07)$ & 0.070 & $(0.15)$ \\
\hline Constant & $0.879 * * *$ & $(8.39)$ & $0.883^{* * *}$ & $(8.56)$ & $0.917^{* * *}$ & $(9.21)$ \\
\hline Observations & 684 & & 684 & & 684 & \\
\hline$R^{2}$ & 0.347 & & 0.347 & & 0.345 & \\
\hline$\overline{\operatorname{diff} \leq \mathrm{k}}$ & $k=3$ & & $k=2$ & & $k=1$ & \\
\hline year-specific FE & No & & No & & No & \\
\hline FIFA ranking & No & & No & & No & \\
\hline
\end{tabular}

${ }^{*} p<0.1,{ }^{* *} p<0.05,{ }^{* * *} p<0.01$ 
Table 12: First OLS specification, controlling for important games, including FIFA ranking

\begin{tabular}{|c|c|c|c|c|c|c|}
\hline & \multicolumn{2}{|c|}{ (1) } & \multicolumn{2}{|c|}{$\overline{(2)}$} & \multicolumn{2}{|c|}{$(3)$} \\
\hline & coef & t-stat & coef & t-stat & coef & t-stat \\
\hline home & $0.808^{* * *}$ & $(5.20)$ & $0.817^{* * *}$ & $(5.26)$ & $0.806^{* * *}$ & $(5.20)$ \\
\hline altitude (HAC) & $0.245^{*}$ & $(1.96)$ & $0.221^{*}$ & $(1.76)$ & $0.243^{*}$ & $(1.91)$ \\
\hline \multicolumn{7}{|l|}{ Incumbent* HAC } \\
\hline Argentina & ref. & & ref. & & ref. & \\
\hline Bolivia & $0.986^{* *}$ & $(1.97)$ & $0.982^{*}$ & $(1.96)$ & $1.031^{* *}$ & $(2.05)$ \\
\hline Brasil & -0.481 & $(-0.93)$ & -0.485 & $(-0.94)$ & -0.494 & $(-0.96)$ \\
\hline Chile & 0.493 & $(0.82)$ & 0.504 & $(0.84)$ & 0.501 & $(0.83)$ \\
\hline Colombia & 0.158 & $(0.29)$ & 0.166 & $(0.31)$ & 0.170 & $(0.31)$ \\
\hline Ecuador & $1.069 * *$ & $(2.04)$ & $1.021^{*}$ & $(1.93)$ & $1.100^{* *}$ & $(2.09)$ \\
\hline Paraguay & 0.067 & $(0.11)$ & 0.060 & $(0.10)$ & 0.076 & $(0.13)$ \\
\hline Peru & 0.464 & $(0.79)$ & 0.452 & $(0.77)$ & 0.468 & $(0.78)$ \\
\hline Uruguay & 0.648 & $(1.12)$ & 0.648 & (1.11) & 0.674 & $(1.15)$ \\
\hline Venezuela & 0.627 & $(1.01)$ & 0.635 & $(1.02)$ & 0.652 & $(1.06)$ \\
\hline \multicolumn{7}{|l|}{ Rival* HAC } \\
\hline Argentina & ref. & & ref. & & ref. & \\
\hline Bolivia & $-1.424 * * *$ & $(-2.82)$ & $-1.383^{* * *}$ & $(-2.75)$ & $-1.441^{* * *}$ & $(-2.82)$ \\
\hline Brasil & 0.107 & $(0.19)$ & 0.143 & $(0.25)$ & 0.086 & $(0.15)$ \\
\hline Chile & -0.681 & $(-1.10)$ & -0.642 & $(-1.03)$ & -0.680 & $(-1.09)$ \\
\hline Colombia & -0.477 & $(-0.87)$ & -0.428 & $(-0.78)$ & -0.471 & $(-0.85)$ \\
\hline Ecuador & $-1.343^{* * *}$ & $(-2.59)$ & $-1.319^{* *}$ & $(-2.55)$ & $-1.356^{* *}$ & $(-2.59)$ \\
\hline Paraguay & -0.390 & $(-0.65)$ & -0.370 & $(-0.61)$ & -0.436 & $(-0.72)$ \\
\hline Peru & -0.732 & $(-1.15)$ & -0.728 & $(-1.15)$ & -0.659 & $(-1.03)$ \\
\hline Uruguay & $-1.106^{*}$ & $(-1.88)$ & $-1.039^{*}$ & $(-1.76)$ & $-1.080^{*}$ & $(-1.80)$ \\
\hline Venezuela & -0.669 & $(-1.09)$ & -0.624 & $(-1.00)$ & -0.675 & $(-1.09)$ \\
\hline \multicolumn{7}{|l|}{ Incumbent dummies } \\
\hline Argentina & ref. & & ref. & & ref. & \\
\hline Bolivia & $-1.238^{* * *}$ & $(-5.05)$ & $-1.243^{* * *}$ & $(-5.06)$ & $-1.248 * * *$ & $(-5.01)$ \\
\hline Brasil & -0.041 & $(-0.19)$ & -0.040 & $(-0.19)$ & -0.026 & $(-0.13)$ \\
\hline Chile & $-0.588 * * *$ & $(-2.61)$ & $-0.586 * * *$ & $(-2.60)$ & $-0.561^{* *}$ & $(-2.47)$ \\
\hline Colombia & $-0.381^{*}$ & $(-1.82)$ & $-0.379^{*}$ & $(-1.78)$ & $-0.371^{*}$ & $(-1.77)$ \\
\hline Ecuador & $-0.802^{* * *}$ & $(-3.50)$ & $-0.776 * * *$ & $(-3.40)$ & $-0.799 * * *$ & $(-3.49)$ \\
\hline Paraguay & -0.158 & $(-0.80)$ & -0.155 & $(-0.78)$ & -0.158 & $(-0.80)$ \\
\hline Peru & $-0.805^{* * *}$ & $(-3.47)$ & $-0.799 * * *$ & $(-3.45)$ & $-0.793^{* * *}$ & $(-3.43)$ \\
\hline Uruguay & $-0.577^{* * *}$ & $(-2.88)$ & $-0.565^{* * *}$ & $(-2.87)$ & $-0.542^{* * *}$ & $(-2.77)$ \\
\hline Venezuela & $-0.942^{* * *}$ & $(-3.38)$ & $-0.945^{* * *}$ & $(-3.40)$ & $-0.932^{* * *}$ & $(-3.33)$ \\
\hline \multicolumn{7}{|l|}{ Rival dummies } \\
\hline Argentina & ref. & & ref. & & ref. & \\
\hline Bolivia & $1.402^{* * *}$ & $(5.40)$ & $1.384^{* * *}$ & $(5.38)$ & $1.387^{* * *}$ & $(5.39)$ \\
\hline Brasil & 0.049 & $(0.29)$ & 0.044 & $(0.26)$ & 0.036 & $(0.21)$ \\
\hline Chile & $0.611^{* * *}$ & $(2.90)$ & $0.606^{* * *}$ & $(2.89)$ & $0.594^{* * *}$ & $(2.82)$ \\
\hline Colombia & $0.397^{*}$ & $(1.96)$ & $0.382^{*}$ & $(1.90)$ & $0.386^{*}$ & $(1.90)$ \\
\hline Ecuador & $0.877^{* * *}$ & $(3.71)$ & $0.869 * * *$ & $(3.67)$ & $0.867^{* * *}$ & $(3.65)$ \\
\hline Paraguay & $0.318^{*}$ & (1.68) & $0.313^{*}$ & $(1.66)$ & 0.310 & $(1.65)$ \\
\hline Peru & $0.827^{* * *}$ & $(3.62)$ & $0.819^{* * *}$ & $(3.60)$ & $0.805^{* * *}$ & $(3.55)$ \\
\hline Uruguay & $0.547^{* * *}$ & $(3.00)$ & $0.540 * * *$ & $(2.99)$ & $0.537^{* * *}$ & $(2.96)$ \\
\hline Venezuela & $1.034^{* * *}$ & $(3.65)$ & $1.027^{* * *}$ & $(3.64)$ & $1.024^{* * *}$ & $(3.62)$ \\
\hline last games & 0.015 & $(0.18)$ & 0.022 & $(0.35)$ & 0.011 & $(0.25)$ \\
\hline $\operatorname{diff}<\mathrm{k}$ & 0.163 & $(1.15)$ & 0.200 & $(1.26)$ & 0.049 & $(0.18)$ \\
\hline$($ last games $) *(\operatorname{diff} \leq \mathrm{k})$ & -0.005 & $(-0.02)$ & -0.039 & $(-0.11)$ & 0.065 & $(0.14)$ \\
\hline Constant & $0.869 * * *$ & $(8.18)$ & $0.874^{* * *}$ & $(8.41)$ & $0.911^{* * *}$ & $(9.08)$ \\
\hline Observations & 684 & & 684 & & 684 & \\
\hline$R^{2}$ & 0.348 & & 0.348 & & 0.345 & \\
\hline$\overline{\operatorname{diff} \leq \mathrm{k}}$ & $k=3$ & & $k=2$ & & $k=1$ & \\
\hline year-specific FE & No & & No & & No & \\
\hline FIFA ranking & Yes & & Yes & & Yes & \\
\hline
\end{tabular}

${ }^{*} p<0.1,{ }^{* *} p<0.05,{ }^{* * *} p<0.01$ 
Table 13: Second OLS specification, controlling for important games

\begin{tabular}{|c|c|c|c|c|c|c|}
\hline & \multicolumn{2}{|c|}{ (1) } & \multicolumn{2}{|c|}{ (2) } & \multicolumn{2}{|c|}{ (3) } \\
\hline & coef & t-stat & coef & t-stat & coef & t-stat \\
\hline home & $0.801^{* * *}$ & $(5.44)$ & $0.809^{* * *}$ & $(5.51)$ & $0.799^{* * *}$ & $(5.42)$ \\
\hline altitude (HAC) & -0.085 & $(-1.06)$ & -0.105 & $(-1.19)$ & -0.073 & $(-0.89)$ \\
\hline altitude felt by incumbent & $-0.799 * * *$ & $(-3.63)$ & $-0.766^{* * *}$ & $(-3.47)$ & $-0.819^{* * *}$ & $(-3.75)$ \\
\hline altitude felt by rival & $0.865^{* * *}$ & $(3.76)$ & $0.865^{* * *}$ & $(3.74)$ & $0.883^{* * *}$ & $(3.82)$ \\
\hline last games & -0.011 & $(-0.14)$ & 0.001 & $(0.01)$ & 0.002 & $(0.05)$ \\
\hline $\operatorname{diff}<\mathrm{k}$ & 0.123 & $(0.92)$ & 0.177 & (1.17) & 0.015 & $(0.06)$ \\
\hline$($ last games $) *($ diff $\leq \mathrm{k})$ & 0.062 & $(0.20)$ & 0.034 & $(0.10)$ & 0.062 & $(0.13)$ \\
\hline Constant & $0.928^{* * *}$ & $(9.75)$ & $0.922^{* * *}$ & $(9.74)$ & $0.960^{* * *}$ & $(10.58)$ \\
\hline$\overline{\text { Observations }}$ & 684 & & 684 & & 684 & \\
\hline$R^{2}$ & 0.332 & & 0.333 & & 0.331 & \\
\hline$\overline{\operatorname{diff}} \leq \mathrm{k}$ & $k=3$ & & $k=2$ & & $k=1$ & \\
\hline Colombia as a LAT & Yes & & Yes & & Yes & \\
\hline year-specific FE & No & & No & & No & \\
\hline incumbent \& rival FE & Yes & & Yes & & Yes & \\
\hline FIFA ranking & No & & No & & No & \\
\hline
\end{tabular}

Incumbent and Rival omitted variables are Argentina.

${ }^{*} p<0.1,{ }^{* *} p<0.05,{ }^{* * *} p<0.01$

Table 14: Second OLS specification, controlling for important games-including FIFA ranking

\begin{tabular}{|c|c|c|c|c|c|c|}
\hline & \multicolumn{2}{|c|}{ (1) } & \multicolumn{2}{|c|}{$\overline{(2)}$} & \multicolumn{2}{|c|}{$(3)$} \\
\hline & coef & t-stat & coef & t-stat & coef & t-stat \\
\hline home & $0.803^{* * *}$ & $(5.43)$ & $0.811^{* * *}$ & $(5.50)$ & $0.800^{* * *}$ & $(5.41)$ \\
\hline altitude (HAC) & -0.090 & $(-1.10)$ & -0.111 & $(-1.24)$ & -0.075 & $(-0.90)$ \\
\hline altitude felt by incumbent & $-0.792^{* * *}$ & $(-3.58)$ & $-0.758^{* * *}$ & $(-3.42)$ & $-0.816^{* * *}$ & $(-3.71)$ \\
\hline altitude felt by rival & $0.863^{* * *}$ & $(3.74)$ & $0.864^{* * *}$ & $(3.73)$ & $0.882^{* * *}$ & $(3.80)$ \\
\hline last games & -0.007 & $(-0.08)$ & 0.004 & $(0.07)$ & 0.003 & $(0.06)$ \\
\hline $\operatorname{diff}<\mathrm{k}$ & 0.139 & $(1.02)$ & 0.190 & $(1.25)$ & 0.029 & $(0.11)$ \\
\hline$($ last games $) *(\operatorname{diff} \leq \mathrm{k})$ & 0.047 & $(0.15)$ & 0.021 & $(0.06)$ & 0.058 & $(0.12)$ \\
\hline Constant & $0.920^{* * *}$ & $(9.53)$ & $0.915^{* * *}$ & $(9.57)$ & $0.956^{* * *}$ & $(10.47)$ \\
\hline Observations & 684 & & 684 & & 684 & \\
\hline$R^{2}$ & 0.333 & & 0.334 & & 0.331 & \\
\hline$\overline{\operatorname{diff} \leq \mathrm{k}}$ & $k=3$ & & $k=2$ & & $k=1$ & \\
\hline Colombia as a LAT & Yes & & Yes & & Yes & \\
\hline year-specific FE & No & & No & & No & \\
\hline incumbent \& rival FE & Yes & & Yes & & Yes & \\
\hline FIFA ranking & Yes & & Yes & & Yes & \\
\hline
\end{tabular}

Incumbent and Rival omitted variables are Argentina.

${ }^{*} p<0.1,{ }^{* *} p<0.05,{ }^{* * *} p<0.01$ 
Table 15: First OLS specification, controlling for important games (accumulated points)

\begin{tabular}{|c|c|c|c|c|c|c|}
\hline & \multicolumn{2}{|c|}{ (1) } & \multicolumn{2}{|c|}{ 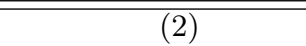 } & \multicolumn{2}{|c|}{$(3)$} \\
\hline & coef & t-stat & coef & t-stat & coef & t-stat \\
\hline home & $0.792^{* * *}$ & $(5.12)$ & $0.796^{* * *}$ & $(5.13)$ & $0.801^{* * *}$ & $(5.19)$ \\
\hline altitude (HAC) & 0.207 & $(1.43)$ & 0.186 & (1.37) & $0.232^{*}$ & (1.77) \\
\hline \multicolumn{7}{|l|}{ Incumbent* HAC } \\
\hline Argentina & ref. & & ref. & & ref. & \\
\hline Bolivia & $1.041^{* *}$ & $(2.08)$ & $1.076^{* *}$ & $(2.15)$ & $1.026^{* *}$ & $(2.04)$ \\
\hline Brasil & -0.499 & $(-0.95)$ & -0.500 & $(-0.97)$ & -0.509 & $(-0.98)$ \\
\hline Chile & 0.576 & $(0.95)$ & 0.583 & $(0.96)$ & 0.488 & $(0.81)$ \\
\hline Colombia & 0.225 & $(0.41)$ & 0.254 & $(0.46)$ & 0.172 & $(0.32)$ \\
\hline Ecuador & $1.128^{* *}$ & $(2.17)$ & $1.153^{* *}$ & $(2.20)$ & $1.148^{* *}$ & $(2.18)$ \\
\hline Paraguay & 0.092 & $(0.16)$ & 0.091 & $(0.15)$ & 0.057 & $(0.10)$ \\
\hline Peru & 0.599 & $(1.02)$ & 0.608 & $(1.02)$ & 0.488 & $(0.81)$ \\
\hline Uruguay & 0.687 & $(1.18)$ & 0.704 & $(1.20)$ & 0.669 & $(1.12)$ \\
\hline Venezuela & 0.711 & $(1.15)$ & 0.711 & $(1.15)$ & 0.645 & $(1.04)$ \\
\hline \multicolumn{7}{|l|}{ Rival $^{*} \mathrm{HAC}$} \\
\hline Argentina & ref. & & ref. & & ref. & \\
\hline Bolivia & $-1.409 * * *$ & $(-2.72)$ & $-1.400 * * *$ & $(-2.71)$ & $-1.356^{* * *}$ & $(-2.63)$ \\
\hline Brasil & 0.067 & $(0.11)$ & 0.064 & $(0.11)$ & 0.111 & $(0.19)$ \\
\hline Chile & -0.696 & $(-1.13)$ & -0.684 & $(-1.11)$ & -0.666 & $(-1.06)$ \\
\hline Colombia & -0.458 & $(-0.82)$ & -0.454 & $(-0.82)$ & -0.461 & $(-0.83)$ \\
\hline Ecuador & $-1.336^{* *}$ & $(-2.53)$ & $-1.351^{* *}$ & $(-2.56)$ & $-1.349^{* *}$ & $(-2.56)$ \\
\hline Paraguay & -0.439 & $(-0.73)$ & -0.442 & $(-0.73)$ & -0.439 & $(-0.72)$ \\
\hline Peru & -0.674 & $(-1.06)$ & -0.672 & $(-1.05)$ & -0.650 & $(-1.02)$ \\
\hline Uruguay & $-1.057^{*}$ & $(-1.78)$ & $-1.084^{*}$ & $(-1.81)$ & $-1.063^{*}$ & $(-1.76)$ \\
\hline Venezuela & -0.659 & $(-1.05)$ & -0.671 & $(-1.07)$ & -0.674 & $(-1.08)$ \\
\hline \multicolumn{7}{|l|}{ Incumbent dummies } \\
\hline Argentina & ref. & & ref. & & ref. & \\
\hline Bolivia & $-1.384 * * *$ & $(-7.89)$ & $-1.355^{* * *}$ & $(-7.88)$ & $-1.304^{* * *}$ & $(-7.70)$ \\
\hline Brasil & -0.035 & $(-0.17)$ & -0.021 & $(-0.10)$ & 0.011 & $(0.06)$ \\
\hline Chile & $-0.642^{* * *}$ & $(-3.38)$ & $-0.622^{* * *}$ & $(-3.27)$ & $-0.575^{* * *}$ & $(-3.03)$ \\
\hline Colombia & $-0.431^{* *}$ & $(-2.03)$ & $-0.416^{* *}$ & $(-1.97)$ & $-0.370^{*}$ & $(-1.78)$ \\
\hline Ecuador & $-0.880 * * *$ & $(-4.34)$ & $-0.864^{* * *}$ & $(-4.22)$ & $-0.868 * * *$ & $(-4.31)$ \\
\hline Paraguay & -0.215 & $(-1.13)$ & -0.210 & $(-1.11)$ & -0.157 & $(-0.85)$ \\
\hline Peru & $-0.919 * * *$ & $(-5.12)$ & $-0.889 * * *$ & $(-5.04)$ & $-0.860 * * *$ & $(-4.99)$ \\
\hline Uruguay & $-0.584^{* * *}$ & $(-3.22)$ & $-0.566^{* * *}$ & $(-3.17)$ & $-0.542^{* * *}$ & $(-3.03)$ \\
\hline Venezuela & $-1.111^{* * *}$ & $(-6.18)$ & $-1.075^{* * *}$ & $(-6.08)$ & $-1.015^{* * *}$ & $(-5.81)$ \\
\hline \multicolumn{7}{|l|}{ Rival dummies } \\
\hline Argentina & ref. & & ref. & & ref. & \\
\hline Bolivia & $1.554^{* * *}$ & $(7.84)$ & $1.526^{* * *}$ & $(7.92)$ & $1.439 * * *$ & $(7.56)$ \\
\hline Brasil & 0.046 & $(0.27)$ & 0.046 & $(0.28)$ & 0.007 & $(0.05)$ \\
\hline Chile & $0.724^{* * *}$ & $(4.08)$ & $0.700^{* * *}$ & $(3.94)$ & $0.661^{* * *}$ & $(3.77)$ \\
\hline Colombia & $0.433^{* *}$ & $(2.15)$ & $0.421^{* *}$ & $(2.10)$ & $0.417^{* *}$ & $(2.07)$ \\
\hline Ecuador & $0.966^{* * *}$ & $(4.44)$ & $0.957 * * *$ & $(4.44)$ & $0.943^{* * *}$ & $(4.39)$ \\
\hline Paraguay & $0.362^{* *}$ & $(2.08)$ & $0.360^{* *}$ & $(2.08)$ & $0.349 * *$ & $(2.00)$ \\
\hline Peru & $0.953^{* * *}$ & $(5.61)$ & $0.943^{* * *}$ & $(5.62)$ & $0.907^{* * *}$ & $(5.42)$ \\
\hline Uruguay & $0.644^{* * *}$ & $(3.69)$ & $0.616^{* * *}$ & $(3.65)$ & $0.570 * * *$ & $(3.45)$ \\
\hline Venezuela & $1.205^{* * *}$ & $(7.13)$ & $1.189^{* * *}$ & $(7.06)$ & $1.174^{* * *}$ & $(6.99)$ \\
\hline last games & -0.012 & $(-0.18)$ & -0.006 & $(-0.11)$ & -0.023 & $(-0.66)$ \\
\hline accumdiff $\leq \mathrm{k}$ & $-0.232^{*}$ & $(-1.86)$ & -0.183 & $(-1.37)$ & -0.098 & $(-0.55)$ \\
\hline last games* accumdiff & 0.033 & $(0.11)$ & 0.063 & $(0.20)$ & $1.183^{* * *}$ & $(4.23)$ \\
\hline Constant & $0.981^{* * *}$ & $(9.32)$ & $0.946^{* * *}$ & $(9.46)$ & $0.905^{* * *}$ & $(9.17)$ \\
\hline Observations & 684 & & 684 & & 684 & \\
\hline$R^{2}$ & 0.349 & & 0.347 & & 0.348 & \\
\hline$\overline{\text { accumdiff } \leq \mathrm{k}}$ & $k=5$ & & $k=3$ & & $k=1$ & \\
\hline year-specific FE & No & & No & & No & \\
\hline FIFA ranking & No & & No & & No & \\
\hline
\end{tabular}

${ }^{*} p<0.1,{ }^{* *} p<0.05,{ }^{* * *} p<0.01$ 
Table 16: First OLS specification, controlling for important games (accumulated points)including FIFA rank

\begin{tabular}{|c|c|c|c|c|c|c|}
\hline & \multicolumn{2}{|c|}{ (1) } & \multicolumn{2}{|c|}{$(2)$} & \multicolumn{2}{|c|}{$(3)$} \\
\hline & coef & t-stat & coef & t-stat & coef & t-stat \\
\hline home & $0.793^{* * *}$ & $(5.12)$ & $0.797 * * *$ & $(5.13)$ & $0.803^{* * *}$ & $(5.19)$ \\
\hline altitude (HAC) & 0.206 & $(1.42)$ & 0.184 & $(1.36)$ & $0.233^{*}$ & $(1.77)$ \\
\hline \multicolumn{7}{|l|}{ Incumbent* HAC } \\
\hline Argentina & ref. & & ref. & & ref. & \\
\hline Bolivia & $1.035^{* *}$ & $(2.09)$ & $1.072^{* *}$ & $(2.16)$ & $1.019^{* *}$ & $(2.05)$ \\
\hline Brasil & -0.505 & $(-0.97)$ & -0.506 & $(-0.99)$ & -0.514 & $(-1.00)$ \\
\hline Chile & 0.569 & $(0.94)$ & 0.577 & $(0.96)$ & 0.479 & $(0.79)$ \\
\hline Colombia & 0.226 & $(0.41)$ & 0.257 & $(0.47)$ & 0.172 & $(0.32)$ \\
\hline Ecuador & $1.124^{* *}$ & $(2.18)$ & $1.152^{* *}$ & $(2.22)$ & $1.145^{* *}$ & $(2.18)$ \\
\hline Paraguay & 0.082 & $(0.14)$ & 0.082 & $(0.14)$ & 0.050 & $(0.08)$ \\
\hline Peru & 0.596 & $(1.01)$ & 0.607 & $(1.02)$ & 0.482 & $(0.80)$ \\
\hline Uruguay & 0.691 & $(1.20)$ & 0.708 & $(1.22)$ & 0.672 & $(1.14)$ \\
\hline Venezuela & 0.721 & $(1.18)$ & 0.721 & $(1.17)$ & 0.654 & $(1.06)$ \\
\hline \multicolumn{7}{|l|}{ Rival* $^{*} \mathrm{HAC}$} \\
\hline Argentina & ref. & & ref. & & ref. & \\
\hline Bolivia & $-1.401^{* * *}$ & $(-2.73)$ & $-1.391^{* * *}$ & $(-2.72)$ & $-1.351^{* * *}$ & $(-2.64)$ \\
\hline Brasil & 0.071 & $(0.12)$ & 0.068 & $(0.12)$ & 0.114 & $(0.19)$ \\
\hline Chile & -0.685 & $(-1.12)$ & -0.673 & $(-1.09)$ & -0.655 & $(-1.05)$ \\
\hline Colombia & -0.456 & $(-0.83)$ & -0.451 & $(-0.82)$ & -0.459 & $(-0.83)$ \\
\hline Ecuador & $-1.331^{* *}$ & $(-2.53)$ & $-1.347^{* *}$ & $(-2.56)$ & $-1.346^{* *}$ & $(-2.57)$ \\
\hline Paraguay & -0.432 & $(-0.71)$ & -0.435 & $(-0.72)$ & -0.432 & $(-0.71)$ \\
\hline Peru & -0.665 & $(-1.04)$ & -0.664 & $(-1.04)$ & -0.641 & $(-1.00)$ \\
\hline Uruguay & $-1.062^{*}$ & $(-1.81)$ & $-1.087^{*}$ & $(-1.84)$ & $-1.067^{*}$ & $(-1.78)$ \\
\hline Venezuela & -0.667 & $(-1.07)$ & -0.680 & $(-1.10)$ & -0.683 & $(-1.11)$ \\
\hline \multicolumn{7}{|l|}{ Incumbent dummies } \\
\hline Argentina & ref. & & ref. & & ref. & \\
\hline Bolivia & $-1.263^{* * *}$ & $(-5.23)$ & $-1.245^{* * *}$ & $(-5.13)$ & $-1.205^{* * *}$ & $(-4.94)$ \\
\hline Brasil & -0.042 & $(-0.20)$ & -0.027 & $(-0.13)$ & 0.007 & $(0.03)$ \\
\hline Chile & $-0.577 * * *$ & $(-2.59)$ & $-0.562^{* *}$ & $(-2.51)$ & $-0.521^{* *}$ & $(-2.33)$ \\
\hline Colombia & $-0.399^{*}$ & $(-1.87)$ & $-0.387^{*}$ & $(-1.82)$ & -0.344 & $(-1.64)$ \\
\hline Ecuador & $-0.810^{* * *}$ & $(-3.61)$ & $-0.801^{* * *}$ & $(-3.53)$ & $-0.811^{* * *}$ & $(-3.60)$ \\
\hline Paraguay & -0.176 & $(-0.87)$ & -0.174 & $(-0.87)$ & -0.126 & $(-0.64)$ \\
\hline Peru & $-0.817^{* * *}$ & $(-3.54)$ & $-0.796^{* * *}$ & $(-3.45)$ & $-0.777 * * *$ & $(-3.42)$ \\
\hline Uruguay & $-0.539 * * *$ & $(-2.80)$ & $-0.525^{* * *}$ & $(-2.75)$ & $-0.507 * * *$ & $(-2.64)$ \\
\hline Venezuela & $-0.962^{* * *}$ & $(-3.46)$ & $-0.940 * * *$ & $(-3.37)$ & $-0.895^{* * *}$ & $(-3.21)$ \\
\hline \multicolumn{7}{|l|}{ Rival dummies } \\
\hline Argentina & ref. & & ref. & & ref. & \\
\hline Bolivia & $1.423^{* * *}$ & $(5.43)$ & $1.398 * * *$ & $(5.40)$ & $1.321^{* * *}$ & $(5.10)$ \\
\hline Brasil & 0.055 & $(0.32)$ & 0.055 & $(0.33)$ & 0.015 & $(0.09)$ \\
\hline Chile & $0.654^{* * *}$ & $(3.11)$ & $0.632^{* * *}$ & $(2.99)$ & $0.597^{* * *}$ & $(2.84)$ \\
\hline Colombia & $0.397^{*}$ & (1.96) & $0.386^{*}$ & $(1.91)$ & $0.384^{*}$ & $(1.90)$ \\
\hline Ecuador & $0.890^{* * *}$ & $(3.72)$ & $0.883^{* * *}$ & $(3.71)$ & $0.875^{* * *}$ & $(3.66)$ \\
\hline Paraguay & $0.321^{*}$ & $(1.72)$ & $0.321^{*}$ & $(1.72)$ & $0.312^{*}$ & (1.67) \\
\hline Peru & $0.843^{* * *}$ & $(3.68)$ & $0.837 * * *$ & $(3.67)$ & $0.807^{* * *}$ & $(3.54)$ \\
\hline Uruguay & $0.599 * * *$ & $(3.20)$ & $0.570^{* * *}$ & $(3.13)$ & $0.528^{* * *}$ & $(2.95)$ \\
\hline Venezuela & $1.043^{* * *}$ & $(3.73)$ & $1.033^{* * *}$ & $(3.68)$ & $1.029 * * *$ & $(3.66)$ \\
\hline last games & -0.016 & $(-0.23)$ & -0.009 & $(-0.18)$ & -0.023 & $(-0.65)$ \\
\hline accumdiff $\leq \mathrm{k}$ & $-0.245^{*}$ & $(-1.95)$ & -0.196 & $(-1.47)$ & -0.109 & $(-0.60)$ \\
\hline last games*accumdiff & 0.050 & $(0.16)$ & 0.091 & $(0.29)$ & $1.197^{* * *}$ & $(4.24)$ \\
\hline Constant & $0.981^{* * *}$ & $(9.32)$ & $0.946^{* * *}$ & $(9.46)$ & $0.905^{* * *}$ & $(9.17)$ \\
\hline Observations & 684 & & 684 & & 684 & \\
\hline$R^{2}$ & 0.351 & & 0.348 & & 0.349 & \\
\hline accumdiff $\leq \mathrm{k}$ & $k=5$ & & $k=3$ & & $k=1$ & \\
\hline year-specific FE & No & & No & & No & \\
\hline FIFA ranking & Yes & & Yes & & Yes & \\
\hline
\end{tabular}

${ }^{*} p<0.1,{ }^{* *} p<0.05,{ }^{* * *} p<0.01$ 
Table 17: First OLS specification, controlling for important games (distance to 5th)-including FIFA rank

\begin{tabular}{|c|c|c|c|c|c|c|}
\hline & \multicolumn{2}{|c|}{ (1) } & \multicolumn{2}{|c|}{$(2)$} & \multicolumn{2}{|c|}{$(3)$} \\
\hline & coef & t-stat & coef & t-stat & coef & t-stat \\
\hline home & $0.812^{* * *}$ & $(5.28)$ & $0.804^{* * *}$ & $(5.18)$ & $0.807^{* * *}$ & $(5.19)$ \\
\hline altitude (HAC) & $0.246^{*}$ & $(1.91)$ & $0.239 *$ & $(1.88)$ & $0.236^{*}$ & $(1.86)$ \\
\hline \multicolumn{7}{|l|}{ Incumbent* HAC } \\
\hline Argentina & ref. & & ref. & & ref. & \\
\hline Bolivia & $1.037^{* *}$ & $(2.07)$ & $1.026^{* *}$ & $(2.06)$ & $1.013^{* *}$ & $(2.03)$ \\
\hline Brasil & -0.451 & $(-0.85)$ & -0.494 & $(-0.95)$ & -0.495 & $(-0.96)$ \\
\hline Chile & 0.540 & $(0.91)$ & 0.512 & $(0.85)$ & 0.521 & $(0.86)$ \\
\hline Colombia & 0.165 & $(0.30)$ & 0.172 & $(0.32)$ & 0.172 & $(0.32)$ \\
\hline Ecuador & $1.106^{* *}$ & $(2.09)$ & $1.130^{* *}$ & $(2.15)$ & $1.099^{* *}$ & $(2.10)$ \\
\hline Paraguay & 0.091 & $(0.15)$ & 0.084 & $(0.14)$ & 0.070 & $(0.12)$ \\
\hline Peru & 0.483 & $(0.80)$ & 0.457 & $(0.76)$ & 0.450 & $(0.76)$ \\
\hline Uruguay & 0.652 & $(1.12)$ & 0.637 & $(1.09)$ & 0.628 & $(1.05)$ \\
\hline Venezuela & 0.656 & $(1.05)$ & 0.639 & (1.03) & 0.650 & $(1.06)$ \\
\hline \multicolumn{7}{|l|}{ Rival* HAC } \\
\hline Argentina & ref. & & ref. & & ref. & \\
\hline Bolivia & $-1.470 * * *$ & $(-2.86)$ & $-1.444^{* * *}$ & $(-2.82)$ & $-1.450 * * *$ & $(-2.84)$ \\
\hline Brasil & 0.143 & $(0.24)$ & 0.092 & $(0.16)$ & 0.110 & $(0.19)$ \\
\hline Chile & -0.723 & $(-1.16)$ & -0.700 & $(-1.12)$ & -0.690 & $(-1.10)$ \\
\hline Colombia & -0.445 & $(-0.81)$ & -0.460 & $(-0.83)$ & -0.443 & $(-0.80)$ \\
\hline Ecuador & $-1.329^{* *}$ & $(-2.54)$ & $-1.363^{* * *}$ & $(-2.60)$ & $-1.350 * *$ & $(-2.56)$ \\
\hline Paraguay & -0.462 & $(-0.76)$ & -0.435 & $(-0.72)$ & -0.423 & $(-0.69)$ \\
\hline Peru & -0.663 & $(-1.03)$ & -0.653 & $(-1.02)$ & -0.623 & $(-0.97)$ \\
\hline Uruguay & $-1.139^{*}$ & $(-1.87)$ & $-1.083^{*}$ & $(-1.81)$ & $-1.079^{*}$ & $(-1.82)$ \\
\hline Venezuela & -0.655 & $(-1.07)$ & -0.665 & $(-1.08)$ & -0.643 & $(-1.03)$ \\
\hline \multicolumn{7}{|l|}{ Incumbent dummies } \\
\hline Argentina & ref. & & ref. & & ref. & \\
\hline Bolivia & $-1.289^{* * *}$ & $(-5.18)$ & $-1.236^{* * *}$ & $(-5.02)$ & $-1.244^{* * *}$ & $(-5.07)$ \\
\hline Brasil & -0.037 & $(-0.18)$ & -0.029 & $(-0.14)$ & -0.020 & $(-0.09)$ \\
\hline Chile & $-0.656^{* * *}$ & $(-2.88)$ & $-0.580^{* *}$ & $(-2.56)$ & $-0.582^{* *}$ & $(-2.57)$ \\
\hline Colombia & $-0.463^{* *}$ & $(-2.15)$ & $-0.397^{*}$ & $(-1.88)$ & $-0.391^{*}$ & $(-1.85)$ \\
\hline Ecuador & $-0.926 * * *$ & $(-3.85)$ & $-0.835^{* * *}$ & $(-3.60)$ & $-0.815^{* * *}$ & $(-3.53)$ \\
\hline Paraguay & -0.193 & $(-0.96)$ & -0.158 & $(-0.80)$ & -0.150 & $(-0.75)$ \\
\hline Peru & $-0.851^{* * *}$ & $(-3.61)$ & $-0.794^{* * *}$ & $(-3.40)$ & $-0.794 * * *$ & $(-3.41)$ \\
\hline Uruguay & $-0.668 * * *$ & $(-3.22)$ & $-0.570 * * *$ & $(-2.83)$ & $-0.581^{* * *}$ & $(-2.85)$ \\
\hline Venezuela & $-0.999 * * *$ & $(-3.49)$ & $-0.932^{* * *}$ & $(-3.28)$ & $-0.944 * * *$ & $(-3.34)$ \\
\hline \multicolumn{7}{|l|}{ Rival dummies } \\
\hline Argentina & ref. & & ref. & & ref. & \\
\hline Bolivia & $1.414^{* * *}$ & $(5.52)$ & $1.393^{* * *}$ & $(5.40)$ & $1.405^{* * *}$ & $(5.44)$ \\
\hline Brasil & 0.062 & $(0.36)$ & 0.039 & $(0.23)$ & 0.040 & $(0.24)$ \\
\hline Chile & $0.610^{* * *}$ & $(2.88)$ & $0.588^{* * *}$ & $(2.80)$ & $0.601^{* * *}$ & $(2.86)$ \\
\hline Colombia & $0.371^{*}$ & $(1.86)$ & $0.385^{*}$ & $(1.91)$ & $0.388^{*}$ & (1.93) \\
\hline Ecuador & $0.839^{* * *}$ & $(3.58)$ & $0.870^{* * *}$ & (3.66) & $0.873^{* * *}$ & $(3.69)$ \\
\hline Paraguay & $0.343^{*}$ & $(1.80)$ & $0.309^{*}$ & $(1.65)$ & $0.320^{*}$ & $(1.71)$ \\
\hline Peru & $0.822 * * *$ & $(3.65)$ & $0.806^{* * *}$ & $(3.56)$ & $0.803^{* * *}$ & $(3.54)$ \\
\hline Uruguay & $0.532^{* * *}$ & $(2.98)$ & $0.529 * * *$ & $(2.94)$ & $0.535^{* * *}$ & $(2.94)$ \\
\hline Venezuela & $1.048^{* * *}$ & $(3.79)$ & $1.023^{* * *}$ & $(3.66)$ & $1.019^{* * *}$ & $(3.65)$ \\
\hline last games & -0.157 & $(-1.27)$ & -0.034 & $(-0.39)$ & -0.005 & $(-0.10)$ \\
\hline distance to $5 \operatorname{th} \leq \mathrm{k}$ & 0.113 & $(1.15)$ & 0.046 & $(0.43)$ & 0.095 & $(0.60)$ \\
\hline last games*distance & 0.335 & $(1.47)$ & 0.148 & $(0.60)$ & 0.188 & $(0.57)$ \\
\hline Constant & $0.887^{* * *}$ & $(8.71)$ & $0.909^{* * *}$ & $(9.06)$ & $0.903^{* * *}$ & $(8.99)$ \\
\hline Observations & 684 & & 684 & & 684 & \\
\hline$R^{2}$ & 0.351 & & 0.346 & & 0.346 & \\
\hline accumdiff $\leq \mathrm{k}$ & $k=2$ & & $k=1$ & & $k=0$ & \\
\hline year-specific FE & No & & No & & No & \\
\hline FIFA ranking & Yes & & Yes & & Yes & \\
\hline
\end{tabular}

${ }^{*} p<0.1,{ }^{* *} p<0.05,{ }^{* * *} p<0.01$ 
Table 18: Second OLS specification, controlling for important games (distance to the 5th position)

\begin{tabular}{|c|c|c|c|c|c|c|}
\hline & \multicolumn{2}{|c|}{ (1) } & \multicolumn{2}{|c|}{$(2)$} & \multicolumn{2}{|c|}{ (3) } \\
\hline & coef & t-stat & coef & t-stat & coef & t-stat \\
\hline home & $0.802^{* * *}$ & $(5.46)$ & $0.798^{* * *}$ & $(5.39)$ & $0.801^{* * *}$ & $(5.41)$ \\
\hline altitude (HAC) & -0.071 & $(-0.93)$ & -0.074 & $(-1.03)$ & -0.097 & $(-1.31)$ \\
\hline altitude felt by incumbent & $-0.811^{* * *}$ & $(-3.71)$ & $-0.829 * * *$ & $(-3.77)$ & $-0.807 * * *$ & $(-3.69)$ \\
\hline altitude felt by rival & $0.884^{* * *}$ & $(3.83)$ & $0.891^{* * *}$ & $(3.85)$ & $0.902^{* * *}$ & $(3.88)$ \\
\hline last games & -0.141 & $(-1.17)$ & -0.041 & $(-0.47)$ & -0.022 & $(-0.44)$ \\
\hline distance to 5 th $\leq \mathrm{k}$ & 0.116 & $(1.20)$ & 0.056 & $(0.54)$ & 0.067 & $(0.43)$ \\
\hline last games*distance & 0.286 & $(1.27)$ & 0.139 & $(0.56)$ & 0.250 & $(0.78)$ \\
\hline Constant & $0.928^{* * *}$ & $(9.83)$ & $0.950^{* * *}$ & $(10.28)$ & $0.948^{* * *}$ & $(10.26)$ \\
\hline Observations & 684 & & 684 & & 684 & \\
\hline$R^{2}$ & 0.336 & & 0.332 & & 0.333 & \\
\hline accumdiff $\leq \mathrm{k}$ & $k=2$ & & $k=1$ & & $k=0$ & \\
\hline Colombia as a LAT & Yes & & Yes & & Yes & \\
\hline year-specific FE & No & & No & & No & \\
\hline incumbent \& rival team $\mathrm{FE}$ & Yes & & Yes & & Yes & \\
\hline
\end{tabular}

Incumbent and Rival omitted variables are Argentina.

${ }^{*} p<0.1,{ }^{* *} p<0.05,{ }^{* * *} p<0.01$ 
Table 19: First OLS specification: Effects of altitude differing between each team, on goal difference

\begin{tabular}{|c|c|c|c|c|}
\hline \multirow[t]{2}{*}{$\overline{\overline{\text { Dependent variable }}}$} & \multicolumn{2}{|c|}{ goalA-goalB } & \multicolumn{2}{|c|}{ Incumbent's points } \\
\hline & coef & t-stat & coef & t-stat \\
\hline home & $1.060^{* * *}$ & $(4.43)$ & $0.804^{* * *}$ & $(5.19)$ \\
\hline altitude (HAC) & -0.000 & . & $0.227^{*}$ & $(1.77)$ \\
\hline \multicolumn{5}{|l|}{ Incumbent* HAC } \\
\hline Argentina & ref. & & ref. & \\
\hline Bolivia & $2.282^{* * *}$ & $(2.84)$ & $1.042^{* *}$ & $(2.08)$ \\
\hline Brasil & -0.117 & $(-0.15)$ & -0.485 & $(-0.94)$ \\
\hline Chile & 1.203 & $(1.42)$ & 0.508 & $(0.84)$ \\
\hline Colombia & 0.430 & $(0.56)$ & 0.168 & $(0.31)$ \\
\hline Ecuador & $1.908^{* *}$ & $(2.46)$ & $1.119^{* *}$ & $(2.13)$ \\
\hline Paraguay & 0.800 & $(0.99)$ & 0.088 & $(0.15)$ \\
\hline Peru & 1.018 & $(1.14)$ & 0.474 & $(0.79)$ \\
\hline Uruguay & 1.135 & $(1.37)$ & 0.674 & $(1.14)$ \\
\hline Venezuela & 0.576 & $(0.58)$ & 0.645 & $(1.04)$ \\
\hline \multicolumn{5}{|l|}{ Rival $^{*} \mathrm{HAC}$} \\
\hline Argentina & ref. & & ref. & \\
\hline Bolivia & $-2.282^{* * *}$ & $(-2.84)$ & $-1.438 * * *$ & $(-2.79)$ \\
\hline Brasil & 0.117 & $(0.15)$ & 0.087 & $(0.15)$ \\
\hline Chile & -1.203 & $(-1.42)$ & -0.682 & $(-1.09)$ \\
\hline Colombia & -0.430 & $(-0.56)$ & -0.474 & $(-0.85)$ \\
\hline Ecuador & $-1.908^{* *}$ & $(-2.46)$ & $-1.354^{* *}$ & $(-2.56)$ \\
\hline Paraguay & -0.800 & $(-0.99)$ & -0.442 & $(-0.72)$ \\
\hline Peru & -1.018 & $(-1.14)$ & -0.657 & $(-1.03)$ \\
\hline Uruguay & -1.135 & $(-1.37)$ & $-1.074^{*}$ & $(-1.77)$ \\
\hline Venezuela & -0.576 & $(-0.58)$ & -0.661 & $(-1.06)$ \\
\hline \multicolumn{5}{|l|}{ Incumbent dummies } \\
\hline Argentina & ref. & & ref. & \\
\hline Bolivia & $-2.210^{* * *}$ & $(-6.83)$ & $-1.336^{* * *}$ & $(-7.80)$ \\
\hline Brasil & 0.276 & $(0.93)$ & -0.022 & $(-0.11)$ \\
\hline Chile & $-0.708^{* * *}$ & $(-2.78)$ & $-0.609 * * *$ & $(-3.17)$ \\
\hline Colombia & -0.414 & $(-1.45)$ & $-0.396^{*}$ & $(-1.89)$ \\
\hline Ecuador & $-1.313^{* * *}$ & $(-4.28)$ & $-0.856^{* * *}$ & $(-4.19)$ \\
\hline Paraguay & $-0.500 * *$ & $(-2.14)$ & -0.188 & $(-1.01)$ \\
\hline Peru & $-1.352^{* * *}$ & $(-5.62)$ & $-0.871^{* * *}$ & $(-4.95)$ \\
\hline Uruguay & $-0.735^{* * *}$ & $(-2.99)$ & $-0.574^{* * *}$ & $(-3.16)$ \\
\hline Venezuela & $-1.676^{* * *}$ & $(-5.91)$ & $-1.045^{* * *}$ & $(-5.92)$ \\
\hline \multicolumn{5}{|l|}{ Rival dummies } \\
\hline Argentina & ref. & & ref. & \\
\hline Bolivia & $2.210^{* * *}$ & $(6.83)$ & $1.501^{* * *}$ & $(7.93)$ \\
\hline Brasil & -0.276 & $(-0.93)$ & 0.022 & $(0.13)$ \\
\hline Chile & $0.708^{* * *}$ & $(2.78)$ & $0.652^{* * *}$ & $(3.73)$ \\
\hline Colombia & 0.414 & $(1.45)$ & $0.415^{* *}$ & $(2.07)$ \\
\hline Ecuador & $1.313^{* * *}$ & $(4.28)$ & $0.935^{* * *}$ & $(4.36)$ \\
\hline Paraguay & $0.500^{* *}$ & $(2.14)$ & $0.342^{*}$ & $(1.97)$ \\
\hline Peru & $1.352^{* * *}$ & $(5.62)$ & $0.900^{* * *}$ & $(5.44)$ \\
\hline Uruguay & $0.735^{* * *}$ & $(2.99)$ & $0.574^{* * *}$ & $(3.45)$ \\
\hline Venezuela & $1.676^{* * *}$ & $(5.91)$ & $1.161^{* * *}$ & $(6.93)$ \\
\hline Constant & $-0.530 * * *$ & $(-4.43)$ & $0.941^{* * *}$ & $(9.50)$ \\
\hline Observations & 684 & & 684 & \\
\hline$R^{2}$ & 0.348 & & 0.345 & \\
\hline year-specific FE & Yes & & Yes & \\
\hline FIFA ranking & No & & No & \\
\hline
\end{tabular}

${ }^{*} p<0.1,{ }^{* *} p<0.05,{ }^{* * *} p<0.01$ 
Table 20: First OLS specification: Effects of altitude differing between each team, on goal difference-including FIFA ranking

\begin{tabular}{|c|c|c|c|c|}
\hline \multirow[t]{2}{*}{$\overline{\bar{D}} \overline{\text { Dependent variable }}$} & \multicolumn{2}{|c|}{ goalA-goalB } & \multicolumn{2}{|c|}{ Incumbent's points } \\
\hline & coef & t-stat & coef & t-stat \\
\hline home & $1.066^{* * *}$ & $(4.44)$ & $0.805^{* * *}$ & $(5.18)$ \\
\hline altitude (HAC) & -0.000 & . & $0.230^{*}$ & $(1.79)$ \\
\hline \multicolumn{5}{|l|}{ Incumbent* HAC } \\
\hline Argentina & ref. & & ref. & \\
\hline Bolivia & $2.259 * * *$ & $(2.86)$ & $1.034^{* *}$ & $(2.08)$ \\
\hline Brasil & -0.136 & $(-0.18)$ & -0.491 & $(-0.95)$ \\
\hline Chile & 1.160 & $(1.39)$ & 0.498 & $(0.83)$ \\
\hline Colombia & 0.422 & $(0.55)$ & 0.164 & $(0.30)$ \\
\hline Ecuador & $1.891^{* *}$ & $(2.47)$ & $1.114^{* *}$ & $(2.13)$ \\
\hline Paraguay & 0.768 & $(0.95)$ & 0.080 & $(0.14)$ \\
\hline Peru & 0.980 & $(1.10)$ & 0.465 & $(0.78)$ \\
\hline Uruguay & 1.144 & $(1.42)$ & 0.674 & $(1.15)$ \\
\hline Venezuela & 0.605 & $(0.63)$ & 0.649 & $(1.06)$ \\
\hline \multicolumn{5}{|l|}{ Rival* HAC } \\
\hline Argentina & ref. & & ref. & \\
\hline Bolivia & $-2.259 * * *$ & $(-2.86)$ & $-1.437 * * *$ & $(-2.80)$ \\
\hline Brasil & 0.136 & $(0.18)$ & 0.090 & $(0.15)$ \\
\hline Chile & -1.160 & $(-1.39)$ & -0.674 & $(-1.08)$ \\
\hline Colombia & -0.422 & $(-0.55)$ & -0.474 & $(-0.85)$ \\
\hline Ecuador & $-1.891^{* *}$ & $(-2.47)$ & $-1.352^{* *}$ & $(-2.57)$ \\
\hline Paraguay & -0.768 & $(-0.95)$ & -0.436 & $(-0.71)$ \\
\hline Peru & -0.980 & $(-1.10)$ & -0.650 & $(-1.01)$ \\
\hline Uruguay & -1.144 & $(-1.42)$ & $-1.076^{*}$ & $(-1.79)$ \\
\hline Venezuela & -0.605 & $(-0.63)$ & -0.669 & $(-1.08)$ \\
\hline \multicolumn{5}{|l|}{ Incumbent dummies } \\
\hline Argentina & ref. & & ref. & \\
\hline Bolivia & $-1.723^{* * *}$ & $(-4.47)$ & $-1.247 * * *$ & $(-5.10)$ \\
\hline Brasil & 0.249 & $(0.83)$ & -0.026 & $(-0.13)$ \\
\hline Chile & -0.442 & $(-1.43)$ & $-0.560 * *$ & $(-2.49)$ \\
\hline Colombia & -0.281 & $(-0.97)$ & $-0.371^{*}$ & $(-1.77)$ \\
\hline Ecuador & $-1.028^{* * *}$ & $(-3.01)$ & $-0.805^{* * *}$ & $(-3.53)$ \\
\hline Paraguay & -0.344 & $(-1.35)$ & -0.159 & $(-0.80)$ \\
\hline Peru & $-0.939 * * *$ & $(-2.95)$ & $-0.796 * * *$ & $(-3.44)$ \\
\hline Uruguay & $-0.558^{* *}$ & $(-2.07)$ & $-0.542^{* * *}$ & $(-2.79)$ \\
\hline Venezuela & $-1.077^{* * *}$ & $(-2.82)$ & $-0.937 * * *$ & $(-3.34)$ \\
\hline \multicolumn{5}{|l|}{ Rival dummies } \\
\hline Argentina & ref. & & ref. & \\
\hline Bolivia & $1.723^{* * *}$ & $(4.47)$ & $1.385^{* * *}$ & $(5.38)$ \\
\hline Brasil & -0.249 & $(-0.83)$ & 0.029 & $(0.18)$ \\
\hline Chile & 0.442 & $(1.43)$ & $0.589^{* * *}$ & $(2.81)$ \\
\hline Colombia & 0.281 & $(0.97)$ & $0.384^{*}$ & $(1.90)$ \\
\hline Ecuador & $1.028^{* * *}$ & $(3.01)$ & $0.867^{* * *}$ & $(3.64)$ \\
\hline Paraguay & 0.344 & $(1.35)$ & 0.305 & $(1.63)$ \\
\hline Peru & $0.939^{* * *}$ & $(2.95)$ & $0.802^{* * *}$ & $(3.55)$ \\
\hline Uruguay & $0.558^{* *}$ & $(2.07)$ & $0.531^{* * *}$ & $(2.94)$ \\
\hline Venezuela & $1.077^{* * *}$ & $(2.82)$ & $1.018^{* * *}$ & $(3.62)$ \\
\hline Constant & $-0.533^{* * *}$ & $(-4.44)$ & $0.937^{* * *}$ & $(9.44)$ \\
\hline Observations & 684 & & 684 & \\
\hline$R^{2}$ & 0.355 & & 0.345 & \\
\hline year-specific FE & Yes & & Yes & \\
\hline FIFA ranking & Yes & & Yes & \\
\hline
\end{tabular}

${ }^{*} p<0.1,{ }^{* *} p<0.05,{ }^{* * *} p<0.01$ 
Table 21: Second OLS specification: Effects of altitude differing between LAT and HAT, on goal difference

\begin{tabular}{|c|c|c|c|c|}
\hline \multirow[t]{2}{*}{$\overline{\overline{\text { Dependent variable }}}$} & \multicolumn{2}{|c|}{ goalA-goalB } & \multicolumn{2}{|c|}{ Incumbent's points } \\
\hline & coef & t-stat & coef & t-stat \\
\hline home & $1.040^{* * *}$ & $(4.64)$ & $0.798^{* * *}$ & $(5.41)$ \\
\hline altitude (HAC) & 0.000 & $(0.00)$ & -0.073 & $(-1.04)$ \\
\hline altitude felt by incumbent & $-1.467^{* * *}$ & $(-4.18)$ & $-0.826^{* * *}$ & $(-3.80)$ \\
\hline altitude felt by rival & $1.467^{* * *}$ & $(4.18)$ & $0.880^{* * *}$ & $(3.81)$ \\
\hline \multicolumn{5}{|l|}{ Incumbent dummies } \\
\hline Argentina & ref. & & ref. & \\
\hline Bolivia & $-2.027^{* * *}$ & $(-6.81)$ & $-1.329 * * *$ & $(-7.49)$ \\
\hline Brasil & 0.256 & $(0.94)$ & -0.096 & $(-0.51)$ \\
\hline Chile & $-0.564^{* *}$ & $(-2.29)$ & $-0.550^{* * *}$ & $(-3.05)$ \\
\hline Colombia & -0.392 & $(-1.60)$ & $-0.390 * *$ & $(-2.14)$ \\
\hline Ecuador & $-1.349^{* * *}$ & $(-4.88)$ & $-0.809^{* * *}$ & $(-4.33)$ \\
\hline Paraguay & $-0.397^{*}$ & $(-1.76)$ & -0.182 & $(-1.04)$ \\
\hline Peru & $-1.237 * * *$ & $(-5.22)$ & $-0.820 * * *$ & $(-4.87)$ \\
\hline Uruguay & $-0.590^{* *}$ & $(-2.49)$ & $-0.494^{* * *}$ & $(-2.86)$ \\
\hline Venezuela & $-1.603^{* * *}$ & $(-5.80)$ & $-0.963^{* * *}$ & $(-5.62)$ \\
\hline \multicolumn{5}{|l|}{ Rival dummies } \\
\hline Argentina & ref. & & ref. & \\
\hline Bolivia & $2.027^{* * *}$ & $(6.81)$ & $1.414^{* * *}$ & $(7.70)$ \\
\hline Brasil & -0.256 & $(-0.94)$ & 0.032 & $(0.19)$ \\
\hline Chile & $0.564^{* *}$ & $(2.29)$ & $0.565^{* * *}$ & $(3.32)$ \\
\hline Colombia & 0.392 & $(1.60)$ & $0.352^{* *}$ & $(1.98)$ \\
\hline Ecuador & $1.349^{* * *}$ & $(4.88)$ & $0.890^{* * *}$ & $(4.62)$ \\
\hline Paraguay & $0.397^{*}$ & $(1.76)$ & 0.279 & $(1.65)$ \\
\hline Peru & $1.237 * * *$ & $(5.22)$ & $0.818^{* * *}$ & $(4.99)$ \\
\hline Uruguay & $0.590^{* *}$ & $(2.49)$ & $0.429^{* * *}$ & $(2.61)$ \\
\hline Venezuela & $1.603^{* * *}$ & $(5.80)$ & $1.076^{* * *}$ & $(6.49)$ \\
\hline Constant & $-0.520^{* * *}$ & $(-4.64)$ & $0.980^{* * *}$ & $(10.65)$ \\
\hline Observations & 684 & & 684 & \\
\hline$R^{2}$ & 0.336 & & 0.331 & \\
\hline year-specific FE & Yes & & Yes & \\
\hline Colombia as a LAT & Yes & & Yes & \\
\hline FIFA ranking & No & & No & \\
\hline
\end{tabular}

${ }^{*} p<0.1,{ }^{* *} p<0.05,{ }^{* * *} p<0.01$ 
Table 22: Second OLS specification: Effects of altitude differing between LAT and HAT, on goal difference-including FIFA ranking

\begin{tabular}{|c|c|c|c|c|}
\hline \multirow[t]{2}{*}{$\overline{\overline{\text { Dependent variable }}}$} & \multicolumn{2}{|c|}{ goalA-goalB } & \multicolumn{2}{|c|}{ Incumbent's points } \\
\hline & coef & t-stat & coef & t-stat \\
\hline home & $1.047^{* * *}$ & $(4.66)$ & $0.800^{* * *}$ & $(5.40)$ \\
\hline altitude (HAC) & 0.000 & $(0.00)$ & -0.074 & $(-1.06)$ \\
\hline altitude felt by incumbent & $-1.459 * * *$ & $(-4.18)$ & $-0.824^{* * *}$ & $(-3.77)$ \\
\hline altitude felt by rival & $1.459^{* * *}$ & $(4.18)$ & $0.879 * * *$ & $(3.79)$ \\
\hline \multicolumn{5}{|l|}{ Incumbent dummies } \\
\hline Argentina & ref. & & ref. & \\
\hline Bolivia & $-1.534^{* * *}$ & $(-4.02)$ & $-1.244^{* * *}$ & $(-5.00)$ \\
\hline Brasil & 0.226 & $(0.83)$ & -0.101 & $(-0.53)$ \\
\hline Chile & -0.298 & $(-1.00)$ & $-0.504^{* *}$ & $(-2.38)$ \\
\hline Colombia & -0.257 & $(-1.03)$ & $-0.367^{* *}$ & $(-1.98)$ \\
\hline Ecuador & $-1.058^{* * *}$ & $(-3.45)$ & $-0.759 * * *$ & $(-3.57)$ \\
\hline Paraguay & -0.242 & $(-0.98)$ & -0.155 & $(-0.82)$ \\
\hline Peru & $-0.820 * * *$ & $(-2.61)$ & $-0.748^{* * *}$ & $(-3.34)$ \\
\hline Uruguay & -0.408 & $(-1.57)$ & $-0.463^{* *}$ & $(-2.50)$ \\
\hline Venezuela & $-0.988 * * *$ & $(-2.64)$ & $-0.858 * * *$ & $(-3.10)$ \\
\hline \multicolumn{5}{|l|}{ Rival dummies } \\
\hline Argentina & ref. & & ref. & \\
\hline Bolivia & $1.534^{* * *}$ & $(4.02)$ & $1.306^{* * *}$ & $(5.15)$ \\
\hline Brasil & -0.226 & $(-0.83)$ & 0.039 & $(0.23)$ \\
\hline Chile & 0.298 & $(1.00)$ & $0.507^{* *}$ & $(2.48)$ \\
\hline Colombia & 0.257 & $(1.03)$ & $0.323^{*}$ & $(1.78)$ \\
\hline Ecuador & $1.058^{* * *}$ & $(3.45)$ & $0.827^{* * *}$ & $(3.78)$ \\
\hline Paraguay & 0.242 & $(0.98)$ & 0.246 & $(1.34)$ \\
\hline Peru & $0.820 * * *$ & $(2.61)$ & $0.727^{* * *}$ & $(3.27)$ \\
\hline Uruguay & 0.408 & $(1.57)$ & $0.390^{* *}$ & $(2.19)$ \\
\hline Venezuela & $0.988^{* * *}$ & $(2.64)$ & $0.942^{* * *}$ & $(3.37)$ \\
\hline Constant & $-0.524 * * *$ & $(-4.66)$ & $0.977^{* * *}$ & $(10.59)$ \\
\hline Observations & 684 & & 684 & \\
\hline$R^{2}$ & $0.3 "$ & & 0.331 & \\
\hline year-specific FE & Yes & & Yes & \\
\hline Colombia as a LAT & Yes & & Yes & \\
\hline FIFA ranking & Yes & & Yes & \\
\hline
\end{tabular}

${ }^{*} p<0.1,{ }^{* *} p<0.05,{ }^{* * *} p<0.01$ 
Table 23: First OLS specification: Effects of altitude coded as 0/1 vs altitude coded as 0/1/2

\begin{tabular}{|c|c|c|c|c|}
\hline \multirow[t]{2}{*}{$\overline{\text { altitude coding }}$} & \multicolumn{2}{|c|}{ HAC $0 / 1 / 2$} & \multicolumn{2}{|c|}{ HAC $0 / 1$} \\
\hline & coef & t-stat & coef & t-stat \\
\hline home & $0.775^{* * *}$ & $(5.12)$ & $0.805^{* * *}$ & $(5.18)$ \\
\hline altitude (HAC) & 0.121 & $(1.17)$ & $0.227^{*}$ & $(1.77)$ \\
\hline \multicolumn{5}{|l|}{ Incumbent* ${ }^{*} \mathrm{AC}$} \\
\hline Argentina & ref. & & ref. & \\
\hline Bolivia & $0.650^{* *}$ & $(2.11)$ & $1.034^{* *}$ & $(2.08)$ \\
\hline Brasil & -0.348 & $(-1.07)$ & -0.491 & $(-0.95)$ \\
\hline Chile & 0.487 & $(1.18)$ & 0.498 & $(0.83)$ \\
\hline Colombia & 0.069 & $(0.20)$ & 0.164 & $(0.3)$ \\
\hline Ecuador & $0.985^{* * *}$ & $(2.66)$ & $1.114^{* *}$ & $(2.13)$ \\
\hline Paraguay & -0.036 & $(-0.10)$ & 0.088 & $(0.14)$ \\
\hline Peru & 0.208 & $(0.60)$ & 0.465 & $(0.78)$ \\
\hline Uruguay & 0.346 & $(1.00)$ & 0.674 & $(1.15)$ \\
\hline Venezuela & 0.436 & $(1.07)$ & 0.649 & $(1.06)$ \\
\hline \multicolumn{5}{|l|}{ Rival* $^{*} \mathrm{HAC}$} \\
\hline Argentina & ref. & & ref. & \\
\hline Bolivia & $-0.874^{* * *}$ & $(-2.73)$ & $-1.437 * * *$ & $(-2.80)$ \\
\hline Brasil & 0.161 & $(0.42)$ & 0.090 & $(0.15)$ \\
\hline Chile & -0.571 & $(-1.36)$ & -0.674 & $(-1.08)$ \\
\hline Colombia & -0.306 & $(-0.81)$ & -0.474 & $(-0.85)$ \\
\hline Ecuador & $-1.058^{* * *}$ & $(-2.76)$ & $-1.352^{* *}$ & $(-2.57)$ \\
\hline Paraguay & -0.199 & $(-0.50)$ & -0.436 & $(-0.71)$ \\
\hline Peru & -0.293 & $(-0.75)$ & -0.650 & $(-1.01)$ \\
\hline Uruguay & -0.619 & $(-1.63)$ & $-1.076^{*}$ & $(-1.79)$ \\
\hline Venezuela & -0.416 & $(-1.01)$ & -0.669 & $(-1.08)$ \\
\hline \multicolumn{5}{|c|}{ Incumbent dummies } \\
\hline Argentina & ref. & & ref. & \\
\hline Bolivia & $-1.290 * * *$ & $(-5.27)$ & $-1.247^{* * *}$ & $(-5.10)$ \\
\hline Brasil & -0.030 & $(-0.15)$ & -0.026 & $(-0.13)$ \\
\hline Chile & $-0.586 * * *$ & $(-2.62)$ & $-0.560 * *$ & $(-2.49)$ \\
\hline Colombia & $-0.374^{*}$ & $(-1.82)$ & $-0.371^{*}$ & $(-1.77)$ \\
\hline Ecuador & $-0.842^{* * *}$ & $(-3.72)$ & $-0.805^{* * *}$ & $(-3.53)$ \\
\hline Paraguay & -0.143 & $(-0.72)$ & -0.159 & $(-0.80)$ \\
\hline Peru & $-0.780 * * *$ & $(-3.38)$ & $-0.796^{* * *}$ & $(-3.44)$ \\
\hline Uruguay & $-0.519 * * *$ & $(-2.68)$ & $-0.542^{* * *}$ & $(-2.79)$ \\
\hline Venezuela & $-0.936^{* * *}$ & $(-3.37)$ & $-0.937 * * *$ & $(-3.34)$ \\
\hline \multicolumn{5}{|l|}{ Rival dummies } \\
\hline Bolivia & $1.433^{* * *}$ & $(5.56)$ & $1.385^{* * *}$ & $(5.38)$ \\
\hline Brasil & 0.011 & $(0.07)$ & 0.029 & $(0.18)$ \\
\hline Chile & $0.602^{* * *}$ & $(2.89)$ & $0.589 * * *$ & $(2.81)$ \\
\hline Colombia & $0.395^{* *}$ & $(1.99)$ & $0.384^{*}$ & $(1.90)$ \\
\hline Ecuador & $0.863^{* * *}$ & $(3.69)$ & $0.867^{* * *}$ & $(3.64)$ \\
\hline Paraguay & 0.284 & $(1.52)$ & 0.305 & $(1.63)$ \\
\hline Peru & $0.772^{* * *}$ & $(3.42)$ & $0.802^{* * *}$ & $(3.55)$ \\
\hline Uruguay & $0.503^{* * *}$ & $(2.79)$ & $0.531^{* * *}$ & $(2.94)$ \\
\hline Venezuela & $1.003^{* * *}$ & $(3.60)$ & $1.018^{* * *}$ & $(3.62)$ \\
\hline Constant & $0.939 * * *$ & $(9.53)$ & $0.916^{* * *}$ & $(9.09)$ \\
\hline Observations & 684 & & 684 & \\
\hline$R^{2}$ & 0.356 & & 0.345 & \\
\hline year-specific FE & Tes & & Tes & \\
\hline FIFA ranking & Yes & & Yes & \\
\hline
\end{tabular}

${ }^{*} p<0.1,{ }^{* *} p<0.05,{ }^{* * *} p<0.01$ 
Table 24: Second OLS specification: Effects of altitude coded as $0 / 1$ vs altitude coded as $0 / 1 / 2$

\begin{tabular}{lllll}
\hline \hline \multirow{2}{*}{ altitude coding } & $(1)$ & $(2)$ & $(3)$ & $(4)$ \\
& HAC $0 / 1 / 2$ & HAC $0 / 1$ & HAC $0 / 1 / 2$ & HAC $0 / 1$ \\
\hline home & $0.853^{* * *}$ & $0.899^{* * *}$ & $0.786^{* * *}$ & $0.800^{* * *}$ \\
altitude (HAC) & $(5.82)$ & $(6.02)$ & $(5.41)$ & $(5.40)$ \\
& -0.067 & -0.086 & $0.123^{*}$ & -0.074 \\
altitude felt by incumbent & $(-1.53)$ & $(-1.26)$ & $(1.90)$ & $(-1.06)$ \\
& $-0.409^{* * *}$ & $-0.448^{*}$ & $-0.755^{* * *}$ & $-0.824^{* * *}$ \\
altitude felt by rival & $(-2.79)$ & $(-1.87)$ & $(-4.44)$ & $(-3.77)$ \\
& $0.466^{* * *}$ & $0.548^{* *}$ & $0.662^{* * *}$ & $0.879^{* * *}$ \\
\hline Observations & $(3.01)$ & $(2.18)$ & $(3.74)$ & $(3.79)$ \\
$R^{2}$ & 684 & 684 & 684 & 684 \\
rank variables & 0.324 & 0.316 & 0.337 & 0.331 \\
year-specific FE & Yes & Yes & Yes & Yes \\
Colombia as a LAT & Yes & Yes & Yes & Yes \\
incumbent \& rival team FE & Yes & No & Yes & Yes \\
\hline \hline
\end{tabular}

Incumbent and Rival omitted variables are Argentina.

${ }^{*} p<0.1,{ }^{* *} p<0.05,{ }^{* * *} p<0.01$ 
Table 25: First OLS specification: Effects of altitude differing between each team

\begin{tabular}{|c|c|c|c|c|c|c|}
\hline & \multicolumn{2}{|c|}{ (1) } & \multicolumn{2}{|c|}{ (2) } & \multicolumn{2}{|c|}{ (3) } \\
\hline & coef & t-stat & coef & t-stat & coef & t-stat \\
\hline home & $0.805^{* * *}$ & $(5.20)$ & $0.805^{* * *}$ & $(5.18)$ & $0.803^{* * *}$ & $(5.18)$ \\
\hline altitude (HAC) & $0.233^{*}$ & $(1.85)$ & $0.230^{*}$ & $(1.79)$ & $0.231^{*}$ & $(1.71)$ \\
\hline \multicolumn{7}{|l|}{ Incumbent* $\mathrm{HAC}$} \\
\hline Argentina & ref. & & ref. & & ref. & \\
\hline Bolivia & $1.033^{* *}$ & $(2.08)$ & $1.034^{* *}$ & $(2.08)$ & $1.020^{* *}$ & $(2.05)$ \\
\hline Brasil & -0.490 & $(-0.95)$ & -0.491 & $(-0.95)$ & -0.515 & $(-1.00)$ \\
\hline Chile & 0.499 & $(0.83)$ & 0.498 & $(0.83)$ & 0.477 & $(0.79)$ \\
\hline Colombia & 0.174 & $(0.32)$ & 0.164 & $(0.30)$ & 0.158 & $(0.29)$ \\
\hline Ecuador & $1.112^{* *}$ & $(2.13)$ & $1.114^{* *}$ & $(2.13)$ & $1.146^{* *}$ & $(2.19)$ \\
\hline Paraguay & 0.080 & $(0.14)$ & 0.080 & $(0.14)$ & 0.048 & $(0.08)$ \\
\hline Peru & 0.467 & $(0.78)$ & 0.465 & $(0.78)$ & 0.477 & $(0.79)$ \\
\hline Uruguay & 0.675 & $(1.15)$ & 0.674 & $(1.15)$ & 0.670 & (1.13) \\
\hline Venezuela & 0.650 & $(1.06)$ & 0.649 & $(1.06)$ & 0.650 & $(1.05)$ \\
\hline \multicolumn{7}{|l|}{ Rival* HAC } \\
\hline Argentina & ref. & & ref. & & ref. & \\
\hline Bolivia & $-1.438 * * *$ & $(-2.82)$ & $-1.437^{* * *}$ & $(-2.80)$ & $-1.349 * * *$ & $(-2.62)$ \\
\hline Brasil & 0.090 & $(0.15)$ & 0.090 & $(0.15)$ & 0.114 & $(0.19)$ \\
\hline Chile & -0.673 & $(-1.08)$ & -0.674 & $(-1.08)$ & -0.657 & $(-1.05)$ \\
\hline Colombia & -0.464 & $(-0.84)$ & -0.474 & $(-0.85)$ & -0.472 & $(-0.85)$ \\
\hline Ecuador & $-1.354^{* *}$ & $(-2.59)$ & $-1.352^{* *}$ & $(-2.57)$ & $-1.343^{* *}$ & $(-2.55)$ \\
\hline Paraguay & -0.435 & $(-0.72)$ & -0.436 & $(-0.71)$ & -0.433 & $(-0.71)$ \\
\hline Peru & -0.649 & $(-1.01)$ & -0.650 & $(-1.01)$ & -0.644 & $(-1.00)$ \\
\hline Uruguay & $-1.076^{*}$ & $(-1.80)$ & $-1.076^{*}$ & $(-1.79)$ & $-1.066^{*}$ & $(-1.77)$ \\
\hline Venezuela & -0.668 & $(-1.08)$ & -0.669 & $(-1.08)$ & -0.684 & $(-1.10)$ \\
\hline last games & & & & & -0.024 & $(-0.68)$ \\
\hline accum points difference $\leq 1$ & & & & & -0.103 & $(-0.57)$ \\
\hline last games*accum points diff & & & & & $1.205^{* * *}$ & $(4.29)$ \\
\hline Observations & 684 & & 684 & & 684 & \\
\hline$R^{2}$ & 0.345 & & 0.345 & & 0.349 & \\
\hline rank variables & Yes & & Yes & & Yes & \\
\hline year-specific FE & No & & Yes & & Yes & \\
\hline incumbent \& rival team FE & Yes & & Yes & & Yes & \\
\hline
\end{tabular}

Incumbent and Rival omitted variables are Argentina.

${ }^{*} p<0.1,{ }^{* *} p<0.05,{ }^{* * *} p<0.01$ 
Table 26: Second OLS specification: Effects of altitude differing between LAT and HAT

\begin{tabular}{|c|c|c|c|c|c|c|}
\hline & \multicolumn{2}{|c|}{$\overline{(1)}$} & \multicolumn{2}{|c|}{$\overline{(2)}$} & \multicolumn{2}{|c|}{$(3)$} \\
\hline & coef & t-stat & coef & t-stat & coef & t-stat \\
\hline$\overline{\text { home }}$ & $0.899^{* * *}$ & $(6.02)$ & $0.800^{* * *}$ & $(5.40)$ & $0.796^{* * *}$ & $(5.38)$ \\
\hline altitude (HAC) & -0.086 & $(-1.26)$ & -0.074 & $(-1.06)$ & -0.020 & $(-0.26)$ \\
\hline altitude felt by incumbent & $-0.448^{*}$ & $(-1.87)$ & $-0.824^{* * *}$ & $(-3.77)$ & $-0.848^{* * *}$ & $(-3.88)$ \\
\hline altitude felt by rival & $0.548^{* *}$ & $(2.18)$ & $0.879^{* * *}$ & $(3.79)$ & $0.840^{* * *}$ & $(3.64)$ \\
\hline last games & & & & & -0.027 & $(-0.79)$ \\
\hline accum points difference $\leq 1$ & & & & & -0.034 & $(-0.19)$ \\
\hline last games*accum points diff & & & & & $1.144^{* * *}$ & $(3.93)$ \\
\hline Observations & 684 & & 684 & & 684 & \\
\hline$R^{2}$ & 0.316 & & 0.331 & & 0.335 & \\
\hline Colombia as a LAT & No & & Yes & & Yes & \\
\hline
\end{tabular}

Incumbent and Rival omitted variables are Argentina.

Rank variables, year-specific FE, and incumbent and rival team FE are included.

${ }^{*} p<0.1,{ }^{* *} p<0.05,{ }^{* * *} p<0.01$ 